\title{
Mass transfer and diffusion of a single bubble rising in polymer solutions
}

\author{
Feishi Xu, Nicolas Dietrich *, Arnaud Cockx and Gilles Hébrard \\ Université de Toulouse; INSA, UPS, INP; LISBP, 135 Av. de Rangueil, F-31077 Toulouse, France \\ *dietrich@insa-toulouse.fr
}

\begin{abstract}
Based on the planar laser-induced fluorescence with Inhibition (PLIF-I) experiments, the mass transfer and diffusion phenomena in the wake of single air bubbles (equivalent diamater 1-1.4 $\mathrm{mm}$ ) rising in various aqueous polymer solutions (PAAm: $0.1 \mathrm{wt} \%-0.5 \mathrm{wt} \%$; Breox: $2 \mathrm{wt} \%-9.1$ $w t \%)$ are investigated. For each fluid medium, liquid-side mass transfer coefficient and the diffusion coefficient were determined and analyzed by considering multiple factors: the rheological properties of the fluid, the concentration of the solute, the hydrodynamics of the bubble, and the contamination effect. The results were compared with cases implemented in nonpolymer solutions to clearly identify the characteristics of mass transfer in the polymer media. In addition, a new method is proposed to determine the diffusion coefficient in the bubble wake. The present research proves that PLIF-I is a promising tool for investigating local gas-liquid mass transfer, even in complex liquid media.
\end{abstract}

Keywords: Bubble, Mass transfer, Diffusion, PLIF-I, Gas-liquid system 


\section{Introduction}

Bubbly flow is commonly used in chemical and biological processes (e.g., chemical reaction, oxidation, fermentation, etc.) to enhance the mass transport rate and/or a chemical reaction rate. Intensive studies have therefore been carried out to investigate the global mass transfer phenomena in industrial-scale bubble-liquid reactors such as packed columns ${ }^{1}$, bubble columns ${ }^{2}$, mechanically agitated contactors ${ }^{3}$ and spray columns ${ }^{4}$. At small scales, it is believed that the local mass transfer can be affected, not only by the hydrodynamic behavior of the bubble but also by the physical and chemical properties of the liquid. Especially for a single bubble system, where the mass transfer is generally very few to be visualized clearly, the mechanism of mass transfer and diffusion around the bubble is still unclear and research in this domain is also insufficient. In early research, fundamental works on local mass transfer were performed mainly by theoretical derivation, with only sporadic attempts to measure the phenomenon experimentally ${ }^{5-7}$. Due to the limitations of experimental equipment, several factors (e.g. complex fluid properties, contamination effect, boundary layer thickness, liquid-flow disturbances close to the interface) having important influence on the mass transfer were not considered in these studies, so the results require verification. This calls for a delicate technique to accurately quantify the mass transfer.

In recent decades, with the development of optical equipment such as high-resolution cameras, powerful lasers and high-performance sensors, it has become feasible to gain new insight into local mass transfer. One of the typical techniques, Planar Laser Induced Fluorescence with Inhibition (PLIF-I), has proved to be a non-intrusive way of visualizing mass transfer. The basic principle of PLIF-I is to introduce a fluorescent dye into the liquid phase. This kind of dye can be excited by the laser and its fluorescence can then be recorded by the camera. Meanwhile, the fluorescence level can be inhibited by the presence of molecules called "quenchers' (oxygen in this study). Thus the concentration of the dissolved gas can be quantified from the variation of the 
fluorescence intensity on the recorded images. The pioneering application of PLIF-I was carried out by Wolff et al. ${ }^{8}$ to measure the concentration gradient near the gas-liquid interface. Then the technique was implemented to visualize the mass transfer around bubbles ${ }^{9,10}$, in the planar gasliquid interface ${ }^{11,12}$, or in Tailor flow ${ }^{13,14}$. Thanks to the discovery of $\mathrm{pH}$-sensitive dye, $\mathrm{CO}_{2}$ molecules can also act as quenchers and make it possible to visualize the mass transfer for a $\mathrm{CO}_{2}$ bubble ${ }^{15-17}$. In the past ten years, PLIF-I has proved to be capable of quantifying the mass transfer in the vicinity of a freely rising bubble or in the bubble wake. A review by Rüttinger et al. ${ }^{18}$ give an overview concerning the application of LIF technique in different gas-liquid systems. The representative work is listed in Table 1 with the gas-liquid types, the bubble size and the result of the quantification. Among them, a new positioning of the optical system was proposed by Francois et al. ${ }^{19}$ to avoid the strong reflection around the bubble caused by the laser flash. The new experimental configuration enables the mass transfer to be visualized at successive instants in a horizontal plane perpendicular to the bubble rising direction. Based on the recorded images, the temporal evolution of the mass transferred in the wake of the bubble can easily be obtained and thus quantified. Based on this work, Jimenez et al. ${ }^{20}$ and Dietrich et al. ${ }^{21}$ have measured the liquid-side mass transfer coefficient and diffusion coefficient, respectively, for an air bubble rising in different non-polymer media (water + glycerol, salt, glucose).

In industrial application, most of the liquid media are polymers as in biological system, cosmetic, food industries, etc. For wastewater treatment, polymers can play as flocculants, coagulants or emulsion breakers to remove the total suspended solids (TSS) and enhance the sedimentation process. However, as shown in Table 1, the mass transfer of a single bubble in polymer solutions has rarely been studied despite the fact that the characteristics of the polymer molecules may have an impact on the mass transfer ${ }^{22}$. Therefore, the purpose of the present study is to extend this work to more complex liquid media: polymer aqueous solutions. Using the technique of Planar Laser-Induced Fluorescence with Inhibition (PLIF-I), the experiments were implemented for single air bubbles (equivalent diamater 1-1.4 mm) rising in the different polymer solutions 
(PAAm: 0.1-0.5 wt\%; Breox: 2-9.1 wt\%). Since Breox solution is a Newtonian fluid while PAAm is non-Newtonian, the rheological properties, as well as other regular physical properties of these two types of fluid, were measured (Section 2.2). For the gas phase, the hydrodynamic properties of the bubble are investigated in Section 2.3. Based the processed images from the experiment, the diffusion coefficient and liquid side mass transfer coefficient are calculated with specific mathematical approaches in Section 2.4. The results are analyzed in Section 3. For each liquid medium, the properties of the liquid phase, such as viscosity, polymer type and concentration of the solute, as well as the hydrodynamics of the bubble, are taken into account and their impact on the mass transfer is estimated. The results are compared to some cases implemented in nonpolymeric solutions mentioned in the literature listed in Table 1.

Table 1. Bibliography of the mass transfer quantification of a freely rising bubble by PLIF-I in the past decade

\begin{tabular}{|c|c|c|c|c|}
\hline Author & Gas & $\begin{array}{c}\text { Bubble Diameter } \\
{[\mathrm{mm}]}\end{array}$ & $\begin{array}{c}\text { Liquid } \\
\text { (aqueous solution) }\end{array}$ & Quantification result \\
\hline $\begin{array}{l}\text { Dani et al., } \\
(2007)^{23}\end{array}$ & $\mathrm{O}_{2}$ & $<1$ & water & image of $\left[\mathrm{O}_{2}\right]$ distribution \\
\hline $\begin{array}{l}\text { Stöhr et al., } \\
(2009)^{17}\end{array}$ & $\mathrm{CO}_{2}$ & $0.5-5$ & water & image of $\left[\mathrm{O}_{2}\right]$ distribution \\
\hline $\begin{array}{c}\text { Hanyu and } \\
\text { Saito, }(2010)^{24}\end{array}$ & $\mathrm{CO}_{2}$ & 2.9 & water & image of $\left[\mathrm{O}_{2}\right]$ distribution \\
\hline $\begin{array}{l}\text { Francois et al., } \\
\qquad(2011)^{19}\end{array}$ & $\mathrm{O}_{2}$ & $0.72 \sim 1.88$ & $\begin{array}{c}\text { water }+ \text { glycerol }(0-80 \\
w t \%)+ \text { ethanol }(0-80 \\
\text { wt } \%)\end{array}$ & $k_{L}: 8.5 \times 10^{-6}-3.3 \times 10^{-4} \mathrm{~m} / \mathrm{s}$ \\
\hline $\begin{array}{l}\text { Kück et al., } \\
(2012)^{25}\end{array}$ & $\mathrm{CO}_{2}$ & 2.9 & water & $k_{L}: 1.5 \times 10^{-4}-3.5 \times 10^{-4} \mathrm{~m} / \mathrm{s}$ \\
\hline $\begin{array}{l}\text { Valiorgue et al., } \\
(2013,2014)^{26,27}\end{array}$ & $\mathrm{CO}_{2}$ & $0.8 \sim 1.5$ & $\begin{array}{c}\text { water ; } \\
\text { water + ethanol }(20 \mathrm{wt} \%) \\
\text { Na2SO3 }\end{array}$ & $\begin{array}{c}k_{L} \text { for water case: } \\
2.00 \times 10^{-4}-4.64 \times 10^{-4} \mathrm{~m} / \mathrm{s}\end{array}$ \\
\hline $\begin{array}{l}\text { Jimenez et al., } \\
\quad(2013)^{20}\end{array}$ & Air & $0.9 \sim 2.24$ & $\begin{array}{c}\text { water + ethanol }(20 \mathrm{wt} \%) \\
\text { NaCl }(1-5 \mathrm{~g} / \mathrm{L}) \\
\text { glucose }(0.5-1 \mathrm{~g} / \mathrm{L}) \\
\text { glycerol }(10-25 \mathrm{wt} \%)\end{array}$ & $\begin{array}{c}k_{L} \text { for water case: } \\
2.49 \times 10^{-4}-4.31 \times 10^{-4} \mathrm{~m} / \mathrm{s}\end{array}$ \\
\hline $\begin{array}{l}\text { Dietrich et al., } \\
(2015)^{21}\end{array}$ & Air & $0.72-1.88$ & glycerol (0-43 wt\%) & $D: 4 \times 10-^{11}-2.09 \times 10^{-9} \mathrm{~m} / \mathrm{s}$ \\
\hline
\end{tabular}




\begin{tabular}{|c|c|c|c|c|}
\hline $\begin{array}{l}\text { Saito and Toriu, } \\
\qquad(2015)^{16}\end{array}$ & $\mathrm{CO}_{2}$ & $\sim 1.16$ & water & {$\left[\mathrm{CO}_{2}\right]=1-2.5 \mathrm{mg} / \mathrm{L}$ in the bubble } \\
\hline $\begin{array}{l}\text { Huang et al. } \\
(2015,2017)^{28,29}\end{array}$ & $\mathrm{CO}_{2}$ & 2.9 & $\begin{array}{l}\text { purified and contaminated } \\
\text { water }\end{array}$ & $\begin{array}{c}k_{L} \text { for } \\
\text { purified water: } 1.5 \times 10^{-4}-3.5 \times 10^{-4} \mathrm{~m} / \mathrm{s} \\
\text { contaminated water: } 0.2 \times 10^{-4}-0.4 \times 10^{-4} \\
\mathrm{~m} / \mathrm{s}\end{array}$ \\
\hline $\begin{array}{l}\text { Xu et al., } \\
(2017)^{30}\end{array}$ & Air & $0.90-1.23$ & water & $D: 1.9 \times 10^{-9}-2 \times 10^{-9} \mathrm{~m} / \mathrm{s}$ \\
\hline $\begin{array}{l}\text { Roudet et al., } \\
\quad(2017)^{31}\end{array}$ & $\mathrm{O}_{2}$ & $5.1-32$ & water + ethanol (20 wt\%) & $S h=1.066 \mathrm{Pe}^{1 / 2}$ \\
\hline $\begin{array}{l}\text { Kong et al., } \\
(2018)^{32}\end{array}$ & $\mathrm{CO}_{2}$ & 1.9 & water & $\begin{array}{c}{\left[\mathrm{CO}_{2}\right]<2.5 \times 10^{-5} \mathrm{~mol} / \mathrm{L} \text { in the core of the }} \\
\text { vortex. }\end{array}$ \\
\hline
\end{tabular}

\section{Materials and Methods}

\subsection{Experimental setup}

The experimental setup, depicted in Fig. 1, was based on the dual camera system ${ }^{19}$. The transparent column [1] was filled with 2 liters of the liquid to be studied and was deoxygenated by bubbling nitrogen before each experiment. A single air bubble was generated by a syringe pump [2] and injected through a stainless steel needle into the column. To excite the fluorescence, a horizontal laser sheet was generated by a Nd:Yag laser [3] and set about $100 \mathrm{~mm}$ above the needle. Then the images of the fluorescence in the wake of the bubble were recorded by a chargecoupled device (CCD) camera [4] located under the column and focused on the laser sheet. A microlens (105 mm f/8, Canon) with an extension tube was applied to obtain an image area of about $10 \times 10 \mathrm{~mm}^{2}$. A $570 \mathrm{~nm}$ high-pass filter was also placed in front of the lens to block the laser light. The laser and the CCD camera were synchronized by a programmable trigger unit [4]. The time was set to 0 when the first picture containing the transferred mass was taken. A highspeed camera [6] was placed orthogonally to the first camera, just next to one side of the column. It was used to record the velocity, shape, and diameter of the bubble (image area $\approx 20 \times 20 \mathrm{~mm}^{2}$ ). The images from these two cameras were then transferred to the acquisition system, which used two professional software packages [7]. In addition, the experimental system was placed in a 
thermostatic environment $\left(20^{\circ} \mathrm{C}\right)$ controlled by an air conditioner. The specific parameters of each instrument were as follows:

1- Column: made of PMMA (polymethylmethacrylate), $100 \times 100 \times 300 \mathrm{~mm}^{3}$;

2- Syringe pump: HARVARD Apparatus PHD 22/2000 Programmable;

3- Nd:YAG laser: DANTEC Dynamics Dualpower 200-15, 15Hz, 2×200 mJ;

4- Synchronizer: DANTEC Dynamics Dualpower

5- CCD camera: DANTEC Dynamics Flowsense CM, 12 bits, 15 fps, 2048×2048 pixels;

6- High-speed camera: Photon SA3, 8 bits, 2000 fps, 1024×1024 pixels;

7- Acquisition system: DynamicStudio 4.0/ Photron FASTCAM Viewer (PFV2)

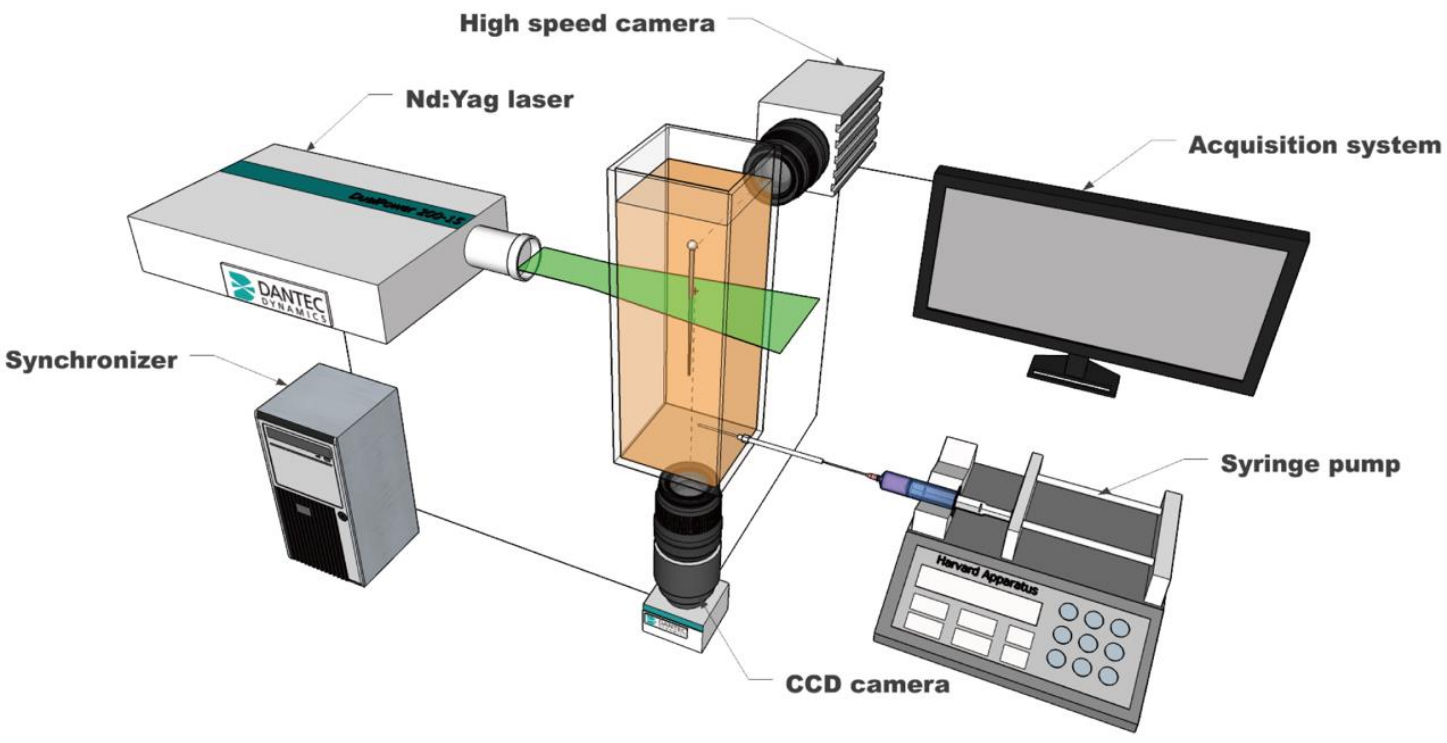

Fig. 1. Experimental setup

\subsection{Materials}

As the objective of our research was to study the mass transfer process in polymer media, two water-soluble polymers were chosen for experiments:

- PAAm (Polyacrylamide, Sigma-Aldrich, CAS: 9003-05-8) 
- $\quad$ Breox $\left(\right.$ BREOX $^{\circledR}$ polyalkylene glycol 75 W 55000, BASF SE, CAS: 137 number 900311-6)

PAAm is versatile and used worldwide to improve commercial products and processes, such as the flocculation of solids in a liquid, and to enhance oil recovery. The average molecular weight of commercial polyacrylamide ranges from approximately $2 \times 10^{3}$ to as high as $15 \times 10^{6} \mathrm{~g} / \mathrm{mol}$. These large molecules of PAAm greatly influence the products' properties as a flocculant and rheology control agent ${ }^{33}$. The aqueous solution of PAAm is one of the most common nonNewtonian fluids and is widely used as the investigated agent in much laboratory research. Breox is a block co-polymer of ethylene glycol and propylene glycol which offers a high 138 viscosity (up to $60 \mathrm{~Pa} . \mathrm{s}$ at $40^{\circ} \mathrm{C}$ ). Breox synthetic fluids provide the base for an extensive range of applications from high-performance industrial lubricants to process aids in food and pharmaceuticals. Unlike that of PAAm, Breox aqueous solution is a Newtonian fluid. So, for comparison, the viscosities of different concentrations of these two types of polymer solutions were measured with a rheometer (HAKKE MARS III, Germany). The viscosities of both solutions increase at higher solute concentrations. However, at a given concentration, the viscosities of Breox solutions remain constant while the PAAm solutions have the apparent shear thinning property that the viscosity decreases at higher shear rates. The specific values of their viscosities are listed in Table 2 with other basic physical properties. It should be indicated that, for the PAAm solutions, the viscosities depend on the shear rate, which, within the investigated range $\left(1 \mathrm{~s}^{-1}<\gamma<100 \mathrm{~s}^{-1}\right)$, can be characterized by the classic power-law model:

$$
\mu=K \gamma^{n-1}
$$

where:

- $\quad \mu$ is the dynamic viscosity $[\mathrm{Pa} \cdot \mathrm{s}]$;

- $K$ is the flow consistency index $\left[\mathrm{Pa} \cdot \mathrm{s}^{\mathrm{n}}\right]$;

- $\gamma$ is the shear rate or the velocity gradient perpendicular to the plane of shear $\left[\mathrm{s}^{-1}\right]$; 
- $\quad n$ is the flow behavior index (dimensionless).

For our operating conditions, shear rates can be estimated from the processed experimental data: rising velocity $U$ and equivalent diameter of the bubble $D_{e q}$ :

$$
\gamma=\frac{U}{D_{e q}}
$$

The method to calculate $U$ and $D_{e q}$ is presented in Sections 2.3.

Table 2. Physical properties of the experimental fluids

\begin{tabular}{lllll}
\hline $\begin{array}{l}\text { Composition } \\
\text { [wt.] }\end{array}$ & & $\begin{array}{l}\boldsymbol{\sigma} \\
{[\mathbf{m N} / \mathbf{m}]}\end{array}$ & $\begin{array}{l}\boldsymbol{\rho} \\
{\left[\mathrm{kg} / \mathbf{m}^{3}\right]}\end{array}$ & $\begin{array}{l}\boldsymbol{\mu} \\
{[\mathbf{m P a} \cdot \mathbf{s}]}\end{array}$ \\
\hline Water & & 72.8 & 998 & 1 \\
+ Breox & $2.00 \%$ & 65.2 & 999 & 2 \\
& $5.50 \%$ & 63.4 & 1007 & 5 \\
& $9.10 \%$ & 60.1 & 1013 & 11 \\
+ PAAm & $0.10 \%$ & 69.8 & 998 & $13 \gamma^{-0.35}$ \\
& $0.25 \%$ & 67.2 & 999 & $16 \gamma^{-0.34}$ \\
& & & & $18 \gamma^{-0.31}$ \\
\hline
\end{tabular}

In addition, to visualize the transferred mass, a ruthenium complex $\left(\mathrm{C}_{36} \mathrm{H}_{24} \mathrm{Cl}_{2} \mathrm{~N}_{6} \mathrm{Ru} \cdot x \mathrm{H}_{2} \mathrm{O}\right.$, Sigma-Aldrich) was mixed with the solutions as the fluorescent dye or fluorophore. Compared with the one used by Jimenez et al..$^{20}$, the main advantage of the dye considered in this study is its direct solubility in water and thus its smaller influence on the mass transfer phenomenon. After testing the fluorescence at different concentrations of the dye ${ }^{34}$, the concentration was set at 75 $\mathrm{mg} / \mathrm{L}$ to guarantee fluorescence efficiency and economy. 


\subsection{Hydrodynamics}

The hydrodynamic properties of the rising bubble were obtained from the sequence of images recorded by the high-speed camera.

To calculate the velocity of the bubble, the centroid $\left(x_{i}, y_{i}\right)$ of the bubble in each image is recognized and processed in Matlab. The distance between the centroids in two successive frames divided by the time interval $\Delta t(1 / 2000 \mathrm{~s})$ gives the rising velocity of the bubble:

$$
\text { Rising velocity: } \quad U_{b}=\frac{y_{i+1}-y_{i}}{\Delta t}
$$

The aspect ratio of the bubble is defined as the ratio between the major axis (width of the bubble: w) and minor axis (length of the bubble: $l$ ) of the bubble profile:

$$
\text { Aspect ratio: } \quad \chi=\frac{w}{l}
$$

With respect to the bubble equivalent diameter, a reconstruction of the three-dimensional bubble is implemented by supposing that the bubble shape is axisymmetric with the minor axis of the bubble profile. Then the solid bubble is divided into a set of small circular conical frustums. For each frustum, the lateral surface area $S_{i}$ and the volume $V_{i}$ are defined as follows:

$$
\begin{gathered}
S_{i}=\pi(R+r) \sqrt{(R-r)^{2}+h^{2}} \\
V_{i}=\frac{1}{3} \pi h\left(R^{2}+r^{2}+R r\right)
\end{gathered}
$$

where $R$ and $r$ the radius of the lower and upper cross-sections, respectively, and $h$ is the height of the frustum. These three variables can be directly obtained from the bubble profile recorded by the high speed camera. The surface area of the bubble is the sum of the lateral surface area of all the small frustums:

$$
\text { Surface area: } \quad S_{b}=\sum_{i=1}^{N} S_{i}
$$


Similarly, the equivalent diameter can be calculated from the total volume of all the small frustums:

$$
\text { Equivalent diameter: } \quad D_{e q}=\sqrt[3]{\frac{6 \sum_{i=1}^{N} V_{i}}{\pi}}
$$

\subsection{Mass transfer}

\subsubsection{Calibration}

The mass transfer in the bubble wake was quantified using the PLIF-I technique. The basic aim of the PLIF-I experiment was to establish the relationship between the gray level in the image and

the actual dissolved oxygen concentration. According to the theory of Stern and Volmer ${ }^{35}$, the fluorescence level is directly related to the quencher concentration in the liquid phase:

$$
\frac{I_{Q}}{I_{0}}=\frac{1}{1+K_{S V}[Q]}
$$

where $K_{S V}$ is the Stern-Volmer constant $(\mathrm{L} / \mathrm{mg}),[Q]$ the quencher concentration $(\mathrm{mg} / \mathrm{L})$, and $I_{Q}$ and $I_{0}$ the fluorescence intensities in the presence and absence of quencher, respectively. Note that fluorescence intensities are determined from the gray levels and the quencher in our study is oxygen. Eq. (9) can be transformed into the following equation:

$$
\frac{1}{G}=\frac{1}{G_{0}}+\frac{K_{S V}}{G_{0}}\left[O_{2}\right]
$$

where $G$ and $G_{0}$ are the gray levels in the presence and absence of oxygen, respectively. It can be shown that the reciprocal of the gray level is proportional to the dissolved oxygen concentration. Thus, for the calibration, images of the fluorescence area were taken in the condition of different dissolved oxygen concentrations. An example of the calibration curve depicting the gray level according to the oxygen concentration is given in Fig. 2 along with a color bar related to the experimental points. It shows that there is a difference of more than 3000 gray levels on the recorded images between fully oxygenated and totally oxygen free solutions, enabling high accuracy of quantification. Furthermore, the slope of the curve is sharper at lower oxygen concentrations since the gray level decreases by more than 1500 levels when the oxygen 
concentration increases from $0.18 \mathrm{mg} / \mathrm{L}$ to $2 \mathrm{mg} / \mathrm{L}$. This indicates that the dye is so sensitive to the presence of the oxygen that the technique is suitable for quantifying delicate mass transfers.

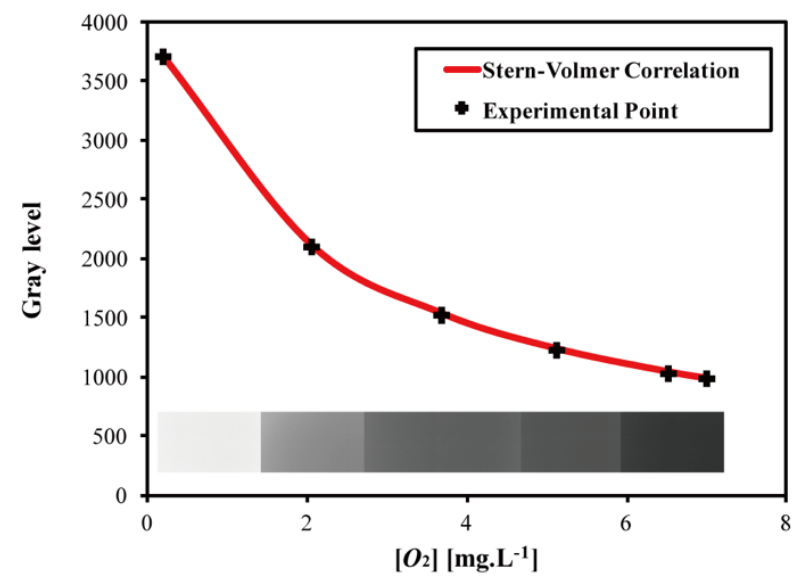

Fig. 2 Calibration curve for water with $75 \mathrm{mg} / \mathrm{L}$ ruthenium complex $\left(G_{0}=4000, K_{S V}=0.44\right.$ L/mg)

The calibration for each fluid tested (Table 2) was performed individually. For all the cases, the measured points fit the Stern-Volmer correlation well, with a coefficient of determination higher than $99 \%$. With this calibration curve, the dissolved oxygen concentration can be obtained from the gray levels recorded in the experiment photos.

\subsubsection{Image processing}

In the optical technique used, there are various possible sources of error that can affect the image during the PLIF-I experiment. The most important one is laser instability. It is impossible to ensure that two laser flashes have absolutely identical intensities and, although the solution presents a uniform oxygen concentration, the image of the oxygen concentration field or gray levels presents an exponential decrease along the laser trajectory through the liquid. This phenomenon, called Beer-Lambert absorption, is commonly used to refer to an attenuation of the laser light during diffusion. Because of these problems, an image processing procedure was implemented using Matlab software, as depicted in Fig. 3, where the dissolved oxygen field is 
presented as a color diffusion spot. It should be noted that the images presented in Fig. 3 have a resolution of about $200 \times 200$ pixels as the border was removed from the original $1024 \times 1024$ pixel image. Nevertheless, the distortion induced by Beer-Lambert absorption can still be visualized. As the laser illuminates from the right side, the oxygen concentration in the right part of the image is slightly higher than that in the left part.

The process consists of, first, subtracting from the raw image (Fig. 3-a) a reference image corresponding to the average of 50 images before the bubble passing. It can be seen that, after the subtraction, the Beer-Lambert distortion is practically eliminated and the background concentration becomes close to $0 \mathrm{mg} / \mathrm{L}$ (Fig. 3-b).

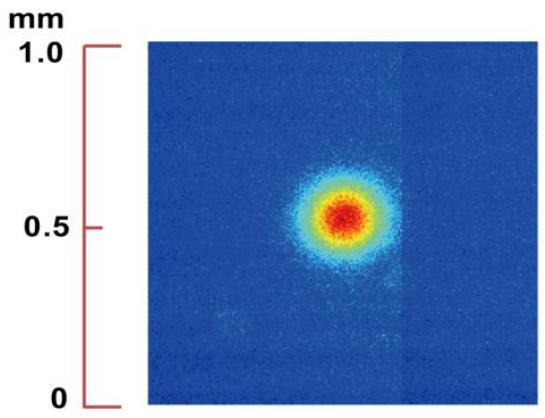

(a)

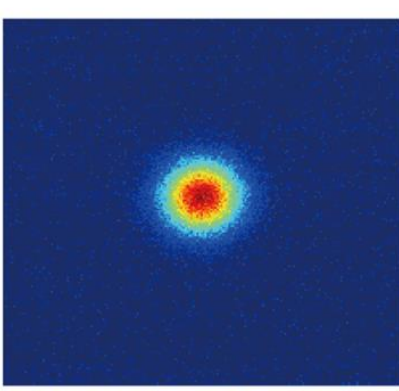

(b)

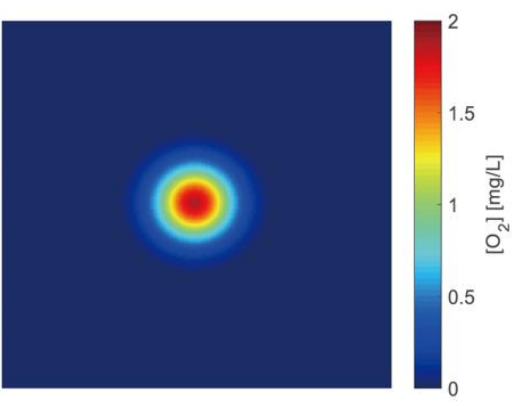

(c)

Fig. 3. Image processing (example of PAAm $0.1 \mathrm{wt} \%$ )

In previous studies ${ }^{19,21}$, it was observed that, for quasi-spherical bubbles, the diffusion spot was circular and presented a Gaussian profile. Thus a fitting model is proposed for the diffusion spot, in which the oxygen concentration $\left[O_{2}\right]$ on the pixel $(x, y)$ is estimated by:

$$
\left[O_{2}\right](x, y)=A \exp \frac{-(x-X)^{2}+(y-Y)^{2}}{B}+C
$$

where $A, B$ are the parameters representing the properties of a Gaussian distribution, $C$ is the mean value of the residual noise on the image, and $(X, Y)$ is the center of the spot. With the 
fminsearch solver (Matlab R2017a), these five parameters were determined by minimizing the error between the measured value $\left[\mathrm{O}_{2}\right]$ and the value from Eq. (11).

After the fitting process, the background noise is automatically removed (Fig. 3-c) and the concentration in the bulk of the image, which does not contain the transfer spot, is uniform. In contrast with the processing method of Jimenez et al. ${ }^{20}$, it is not necessary to analyze the distribution of oxygen concentration in the bulk, because the background impact is already considered in the fitting equation (Eq. (11)). Thus the real oxygen concentration field can be expressed by the following equation, where the term $C$ is removed. The parameters $A, B$, and $C$ are discussed in greater detail in Section 3.1.

$$
\left[O_{2}\right](x, y)=A \exp \frac{-(x-X)^{2}+(y-Y)^{2}}{B}
$$

\subsubsection{Determination of the diffusion coefficient}

In a study by $\mathrm{XU}$ et al. $^{30}$, the chi-squared distribution in statistics theory is introduced to characterize the diffusion phenomenon. Within the area $S_{s p o t}$ on the diffusion spot image (indicated by the red dotted line in Fig. 4), the relationship between the diffusing oxygen concentration field and probability property of the chi-squared distribution is given by the following equation:

$$
\frac{\iint_{S_{\text {spot }}}\left[\mathrm{O}_{2}\right](r, \theta) r d r d \theta}{M}=1-e^{-\frac{\eta}{2}}
$$

where $M$ and $\left[\mathrm{O}_{2}\right](r, \theta)$ are the total transferred mass and the oxygen concentration on the circular spot plan. The right hand term of Eq. (13) denotes the cumulative possibility $P(\eta)$ of a chi-squared distribution of 2 degrees of freedom with a positive integer parameter $\eta$. From Eq. (13), it is deduced that, once the value $\eta$ is fixed, the ratio between the oxygen diffusing within the area $S$ and the total transferred mass $M$ will stay constant. Since the mass transfer in the 
vertical direction is already neglected, the total transferred mass, $M$, on the cross-section of the bubble wake is also constant and the diffusion is assumed to occur only in the fluorescence plane. Therefore, the area $S_{\text {spot }}$ will expand when the oxygen diffuses from the spot center to the surroundings. Obviously, the speed of expansion depends on the diffusion coefficient.

For the quasi-circular spot of radius $R$, the area, $S_{\text {spot }}$, is given $\operatorname{as}^{30}$ :

$$
S_{\text {spot }}=\pi R^{2}=2 \pi \eta D t
$$

From Eq. (14), for constant $D$ and a chosen $\eta$, the area, $S_{\text {spot, }}$ expands linearly with time $t$. The speed of expansion is related to the slope of the curve $S_{\text {spot }}-t$ and the diffusion coefficient $D$ can thus be determined. 


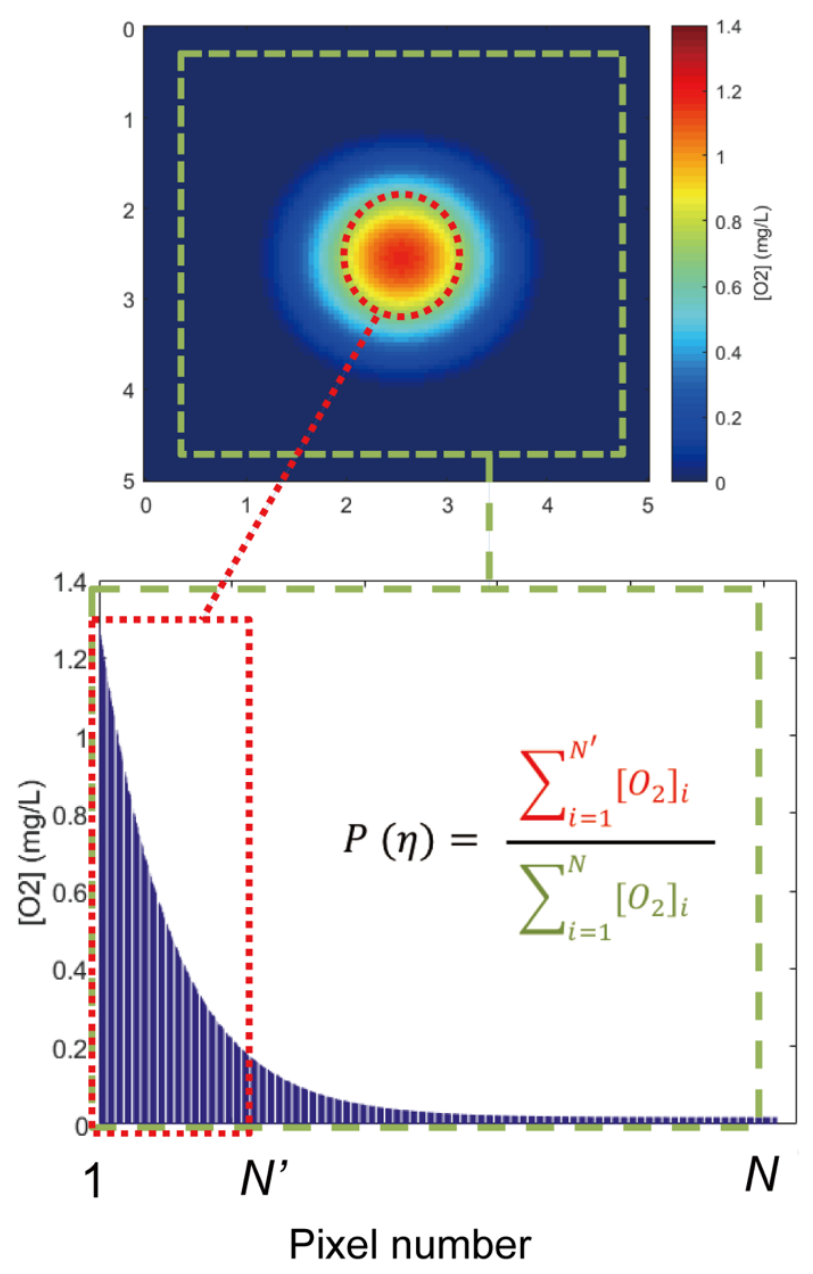

Fig. 4 Determination of the diffusion coefficient ( $N$ : total number of pixels on the image, $N^{\prime}$ : number of pixels within area $S_{\text {spot }},\left[\mathrm{O}_{2}\right]_{i}$ : oxygen concentration at $i$ pixel)

The area $S_{\text {spot }}$ can be obtained from a processed image from which the noise has been removed (expressed by Eq. (12)). As depicted in Fig. 4, the following steps were implemented:

1) Choose $\eta$ and calculate $P(\eta)$;

2) Sort the concentrations in all the pixels $N$ in descending order;

3) Sum all the oxygen concentrations (indicated by green color);

4) Perform a cumulative sum to achieve the proportion $P(\eta)$ of the total concentration (indicated by red color);

5) Count the number of pixels $N^{\prime}$ forming this cumulative sum;

6) Multiply the number by the surface of a single pixel $\delta^{2}$ to obtain $S_{\text {spot }}$ 


\subsubsection{Determination of the liquid side mass transfer coefficient}

With the dissolved oxygen concentration field, mass transfer can be quantified. The mathematical approach used to calculate the mass transfer coefficient is based on a previous study by Francois

et al. ${ }^{19}$. It is assumed that, when the bubble has passed far enough from the investigated plane (fluorescence plane in this study), the effect induced by the bubble passing or the convection can be neglected. Thus the total flow rate of mass transfer from the bubble can be approximated as:

$$
F_{O_{2}}=\frac{d m_{O_{2}}}{d t}
$$

with $m_{\mathrm{O}_{2}}$ the mass of oxygen transferred by the bubble.

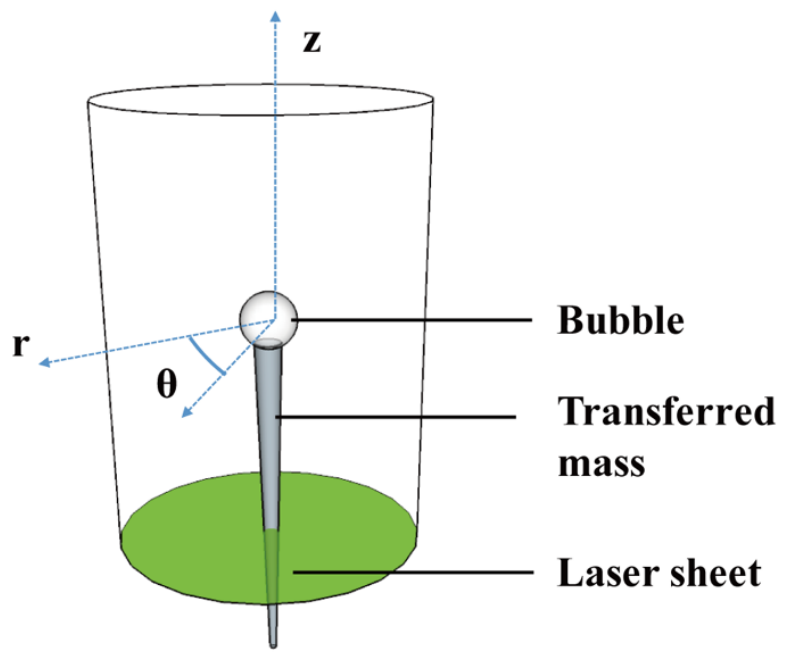

Fig. 5 Description of the mass balance domain

Mass transfer can then be tracked by the oxygen accumulation in the distant wake. Under a cylindrical coordinate system $(r, \theta, z)$, as depicted in Fig. 5, the accumulation term can be written in volume $V$ as:

$$
\begin{aligned}
F_{O_{2}} & =\frac{d m_{O_{2}}}{d t}=\lim _{\Delta t \rightarrow 0} \frac{m_{O_{2}}(t+\Delta t)-m_{O_{2}}(t)}{\Delta t} \\
& =\lim _{\Delta z \rightarrow 0} \frac{\iiint_{V(z)}^{V(z+\Delta z)}\left[O_{2}\right](r, \theta, z) d V}{\int_{z}^{z+\Delta z} d z / U_{b}}
\end{aligned}
$$


Away from the bubble, the variation of the oxygen concentration $\left[O_{2}\right](r, \theta, z)$ in the $\mathrm{z}$ direction can be neglected compared with the variation along the $r$ direction, which implies $\left[O_{2}\right](r, \theta, z)=$ $\left[\mathrm{O}_{2}\right](r, \theta)$. Thus Eq. (16) can be simplified as:

$$
\begin{aligned}
& F_{O_{2}}=\lim _{\Delta z \rightarrow 0} \frac{\int_{z}^{z+\Delta z} d z \iint\left[O_{2}\right](r, \theta) r d r d \theta}{\int_{z}^{z+\Delta z} d z / U_{b}} \\
& =U_{b} \iint\left[O_{2}\right](r, \theta) r d r d \theta=U_{b} \cdot M
\end{aligned}
$$

where $M$ is defined as the total mass transferred on the infinite cross-section in the bubble wake. In the study, this cross-section refers to the investigated plane where the fluorescence occurs and the dissolved oxygen concentration field (containing the diffusion spot) is recorded by the camera.

In the general case, whatever the shape of the diffusion spot, the transferred mass, $M$, can be calculated simply as the sum of the oxygen concentrations $\left[\mathrm{O}_{2}\right]_{i}$ in all pixels on the experimental image (Fig. 3-b):

$$
M=\sum\left[O_{2}\right]_{i} \delta^{2}
$$

where $\delta^{2}$ is the area of a square pixel $\left(\mathrm{mm}^{2}\right)$.

If the spot is circular, the concentration field on the image is assumed to have a Gaussian distribution. As already presented in Section 2.4.2, the concentration field can be fitted by Eq. (11). Thus the transferred mass $M$ can be calculated directly as follows:

$$
M=\pi A B
$$

Based on the knowledge of $M$ and the bubble rising velocity $U_{b}$, the flow rate $F_{O_{2}}$ can be obtained (Eq. (17)). Then the flux density $j_{O_{2}}$ can be deduced using the bubble surface area $S$ (Eq. (7)) and, finally, the liquid side mass transfer coefficient $k_{L}$ is equal to the flux density $j_{O_{2}}$ divided by the driving force $\left(\left[\mathrm{O}_{2}\right]_{\text {sat }}-\left[\mathrm{O}_{2}\right]_{\text {bulk }}\right)$ :

$$
\begin{gathered}
j_{O_{2}}=\frac{F_{O_{2}}}{S_{b}} \\
k_{L}=\frac{j_{O_{2}}}{\left[O_{2}\right]_{s a t}-\left[O_{2}\right]_{\text {bulk }}}
\end{gathered}
$$


where $\left[\mathrm{O}_{2}\right]_{\text {sat }}$ and $\left[\mathrm{O}_{2}\right]_{\text {bulk }}$ are the oxygen concentrations at saturation and far away from the mass transferred by the bubble, respectively. These two values were previously determined using an optical oxygen probe (HACH HQd Portable Meter + IntelliCAL LDO Probe) in a deoxygenated and a saturated solution for each liquid investigated.

\subsubsection{Contamination angle}

According to the stagnant cap model by Sadhal and Johnson ${ }^{36}$, for a bubble whose interface is partially covered by a stagnant layer of surfactant, a cap angle $\varphi_{\text {cap }}$ can be proposed to denote this non-slip region as presented in Fig. 6. Thus when $\varphi_{\text {cap }}=0^{\circ}$ the bubble is clean and when $\varphi_{\text {cap }}=180^{\circ}$, the bubble is fully contaminated. The cap angle can be calculated by the equation for a spherical bubble.

$$
C_{D}^{*}\left(\varphi_{c a p}\right)=\frac{C_{D}-C_{D}^{m}}{C_{D}^{i m}-C_{D}^{m}}=\frac{1}{2 \pi}\left(2 \varphi_{c a p}+\sin \left(\varphi_{c a p}\right)-\sin \left(2 \varphi_{c a p}\right)-\frac{1}{3} \sin \left(3 \varphi_{c a p}\right)\right)
$$

where $C_{D}$ is the drag coefficient of the bubble. $C_{D}^{m}$ and $C_{D}^{i m}$ are the drag coefficients for a clean bubble and for a fully contaminated one, respectively.

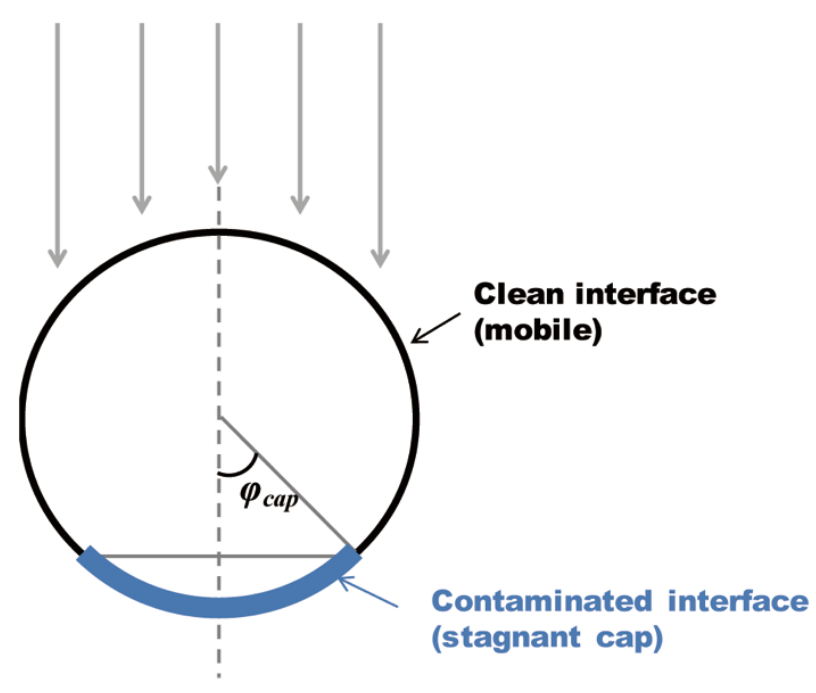

Fig. 6 Stagnant cap model 
Since the Reynolds numbers in our study are small $(R e<100)$, this equation is applicable by considering the correlations of Schiller and Naumann ${ }^{37}$ and Mei et al. ${ }^{38}$ :

$$
\begin{gathered}
C_{D}^{i m}=\frac{24}{R e}\left(1+0.15 R e^{0.687}\right) \\
C_{D}^{m}=\frac{16}{R e}\left(1+\frac{R e}{8+0.5\left(R e+3.315 R e^{0.5}\right)}\right)
\end{gathered}
$$

The expression of the drag coefficient results from the buoyancy and drag force for an isolated bubble rising at terminal velocity:

$$
C_{D}=\frac{4}{3} \frac{g D_{e q}}{U^{2}}
$$

The equation above is valid for spherical bubbles. Although some bubbles in our study were ellipsoidal, their aspect ratios were relatively close to 1 . So this approach can still be used for the contamination angle and drag coefficient calculation.

\section{Results and discussion}

\subsection{Oxygen concentration distribution in the bubble wake}

Thanks to the two cameras system, the hydrodynamic behavior and the mass transfer were both recorded. For the hydrodynamics, the detailed results of all the experimental cases are shown in Table 3. It can be seen that, although generated under the same conditions (identical nozzle, flow rate, etc.), the results depend on the type of fluid. In the Breox solutions, the bubble is larger and the equivalent diameter of the bubble increases $(1.16-1.4 \mathrm{~mm})$ with a higher concentration of the solute. In other cases, the equivalent diameter of the bubble stays close to $1 \mathrm{~mm}$ and the impact of the concentration on the bubble size is not significant. For a bubble at this scale, the rising trajectory is nearly rectilinear as visualized by the high-speed camera. Regarding the bubble 
shape, the bubble is more spherical in polymer media than in water. The reason is believed to be related to the higher viscosity of the polymer fluids. Despite this, the aspect ratios are close to 1 for all the cases, thus the bubbles in this study can be assumed to be quasi-spherical. In addition, the bubble rises more slowly in polymer media, making it more reasonable to neglect the influence of the convection caused by the bubble motion on the mass transfer in the bubble wake.

\section{Table 3. Hydrodynamics results}

\begin{tabular}{|c|c|c|c|c|c|c|c|}
\hline $\begin{array}{l}\text { Composition } \\
\text { [wt.] }\end{array}$ & & $\begin{array}{l}d_{e q} \\
{[\mathrm{~mm}]}\end{array}$ & $\begin{array}{l}U_{b} \\
{[\mathbf{m m} / \mathbf{s}]}\end{array}$ & $\bar{\chi}$ & $\overline{R e}$ & $C_{D}$ & $\begin{array}{l}\varphi_{c a p} \\
{\left[{ }^{\circ}\right]}\end{array}$ \\
\hline Water & & $1.02 \pm 0.02$ & $268.54 \pm 1.69$ & 1.10 & 273 & 0.18 & 29 \\
\hline \multirow[t]{3}{*}{+ Breox } & $2.00 \%$ & $1.16 \pm 0.01$ & $113.15 \pm 1.02$ & 1.20 & 66 & 1.19 & 100 \\
\hline & $5.50 \%$ & $1.33 \pm 0.01$ & $100.88 \pm 1.21$ & 1.02 & 28 & 1.71 & 81 \\
\hline & $9.10 \%$ & $1.40 \pm 0.01$ & $86.58 \pm 0.71$ & 1.02 & 11 & 2.44 & 39 \\
\hline \multirow[t]{3}{*}{ + PAAm } & $0.10 \%$ & $1.00 \pm 0.01$ & $81.14 \pm 0.92$ & 1.04 & 30 & 1.99 & 117 \\
\hline & $0.25 \%$ & $1.00 \pm 0.01$ & $69.83 \pm 0.77$ & 1.00 & 18 & 2.66 & 112 \\
\hline & $0.50 \%$ & $1.03 \pm 0.01$ & $62.28 \pm 0.48$ & 1.00 & 12 & 3.47 & 119 \\
\hline
\end{tabular}

For the mass transfer, examples of the corrected images (Fig. 3-b) are given in Fig. 7, which shows the evolution of the oxygen concentration field in the cross-section of the bubble wake (recorded every $5 / 15 \mathrm{~s}$ as the laser frequency was $15 \mathrm{~Hz}$ ) for three different fluids (water, Breox $2.2 \mathrm{wt} \%$, and PAAm $0.1 \mathrm{wt} \%$ ), with the corresponding bubble shapes given at the top of the figure. Some results are immediately visible on this figure. The oxygen spot expands as a function of time and the oxygen diffuses from the image center to the surroundings. As the bubble is quasi-spherical, the transferred mass is presented as a circular diffusion spot and the concentration distribution shows centrosymmetry. If the diffusion spots are compared for the 
three cases, it is obvious that the mass transferred in polymer media is much less than that in water. Moreover, at the same moment, for the small concentration (Breox $2.2 \mathrm{wt} \%$, and PAAm $0.1 \mathrm{wt} \%$ ), the dissolved oxygen concentrates more at the center in the PAAm solution than in Breox solution even though the total mass transfer is basically the same in these two cases. The phenomenon is believed to be related to their rheological properties and needs further investigation.

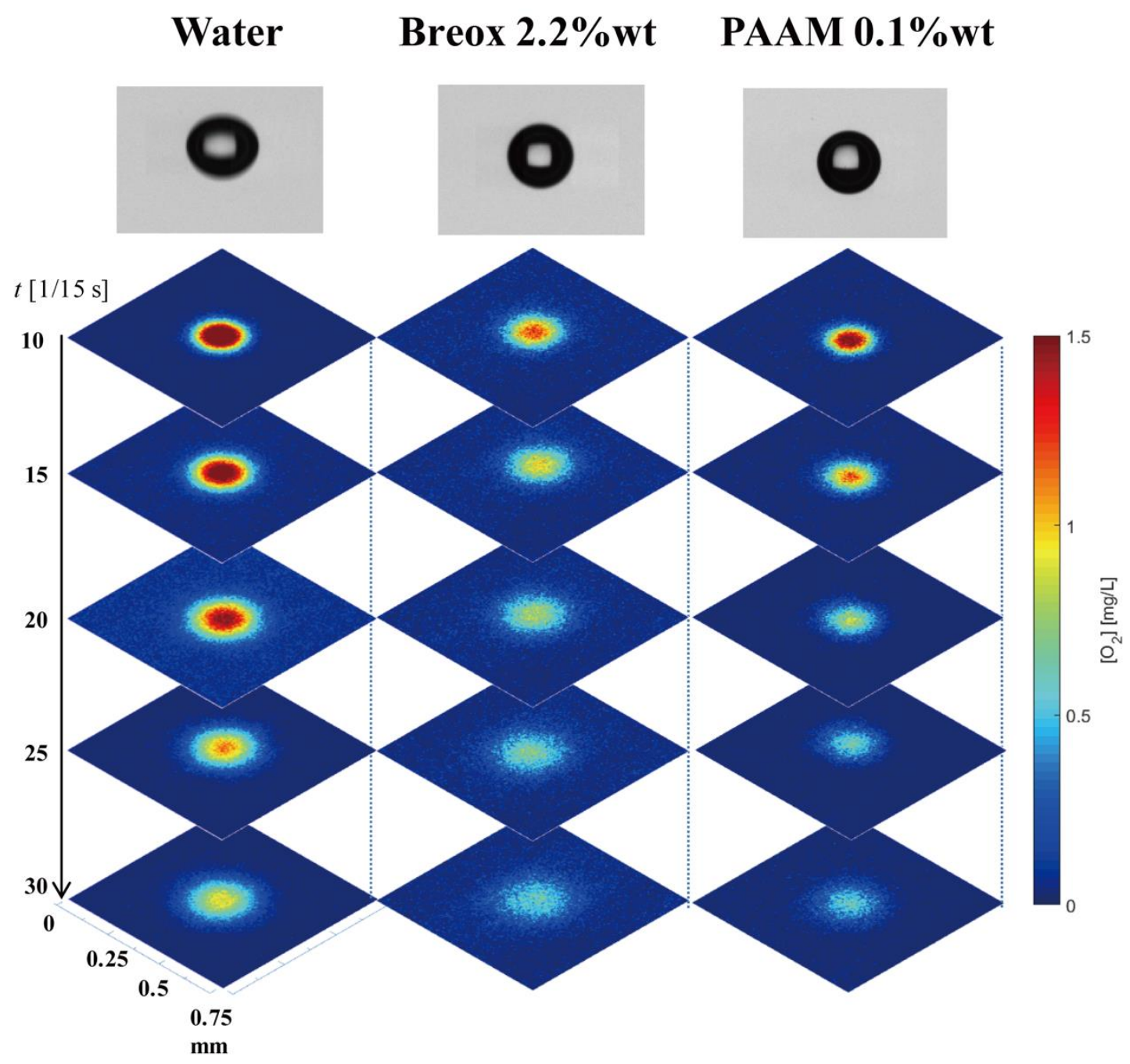

Fig. 7 Examples of corrected images and shapes of a single bubble rising in water, Breox 2.2 wt\% and PAAm 0.1 wt\% solutions 
As presented in Section 2.4.2, a Gaussian model (Eq. (12)) is proposed for fitting the corrected oxygen concentration field. Thus we can study the evolution of the concentration field by investigating the temporal evolution of the values of three parameters, $A, B, C$, of the Gaussian model (Eq. (12)). The result of the PAAm $0.1 \mathrm{wt} \%$ case is shown in Fig. 8. It can be seen that the parameter $A$, which refers to the peak value of the concentration field, has an exponential decay. The peak value decreases by $90 \%$ in the first 3 seconds. The mass transferred on the cross-section of the bubble wake seems to diffuse quickly from the point source to an infinite plane.

On the other hand, the parameter $B$ increases linearly with time. When the $B$ values are correlated with the linear function, the coefficient of determination is $99 \%$, showing the great linearity of the evolution of the parameter $B$. This property is believed to be related to the diffusion coefficient. According to the study by Dietrich et al. ${ }^{21}$, for the substance diffusing from a point source on an infinite plane surface, the instantaneous concentration can be expressed as follows (for the oxygen diffusion in this study):

$$
\left[O_{2}\right]=\frac{M}{4 \pi D t} \exp \left(-\frac{r^{2}}{4 D t}\right)
$$

By comparing Eq. (26) and Eq. (12), it is easily found that:

$$
B=4 D t
$$

Thus, the slope of the curve $B-t$ (Fig. 8-B) is equal to $4 \mathrm{D}$ and this provides an alternative way to estimate the diffusion coefficient. The details are discussed in Section 3.2.

In addition, the value of parameter $C$ scatters with time because it refers to the background noise. As expected, the parameter $C$ can quantify the background impact, caused by the remaining transferred mass or the instability of the laser. However, the majority of the values of $C$ are between $-0.1 \mathrm{mg} / \mathrm{L}$ and $0.1 \mathrm{mg} / \mathrm{L}$, indicating the reliability of the image recording and acquisition system. 

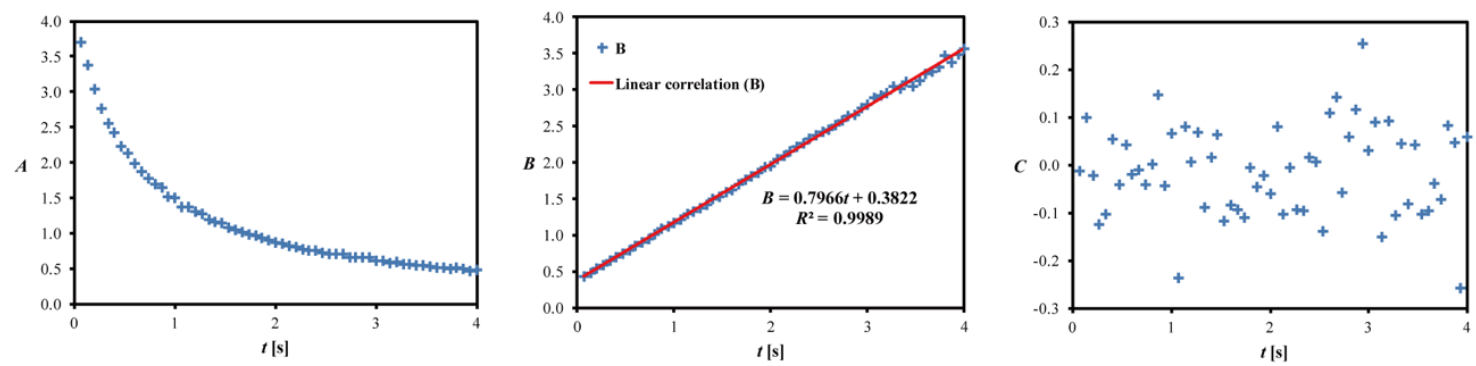

Fig. 8 Evolution of the values of three parameters $A, B, C$ as function of time (Example of the PAAm $0.1 \mathrm{wt} \%$ case)

\subsection{Diffusion coefficient in different polymer medias}

The diffusion phenomenon on the cross-section of the bubble wake has been displayed in Fig. 7. In order to quantify the diffusion, the profile of the dissolved concentration fields is investigated. The profile is obtained by using Eq. (12). Since the oxygen concentration field has a centrosymmetric distribution, only one profile containing the symmetry axis is plotted for each moment. The results of six consecutive moments with the time interval $\Delta t=\frac{10}{15} \mathrm{~s}$ are shown in Fig. 9 for Breox solutions and Fig. 10 for PAAm cases. The total mass transfer $M$ defined by Eq. (19) is also given in the figures. 

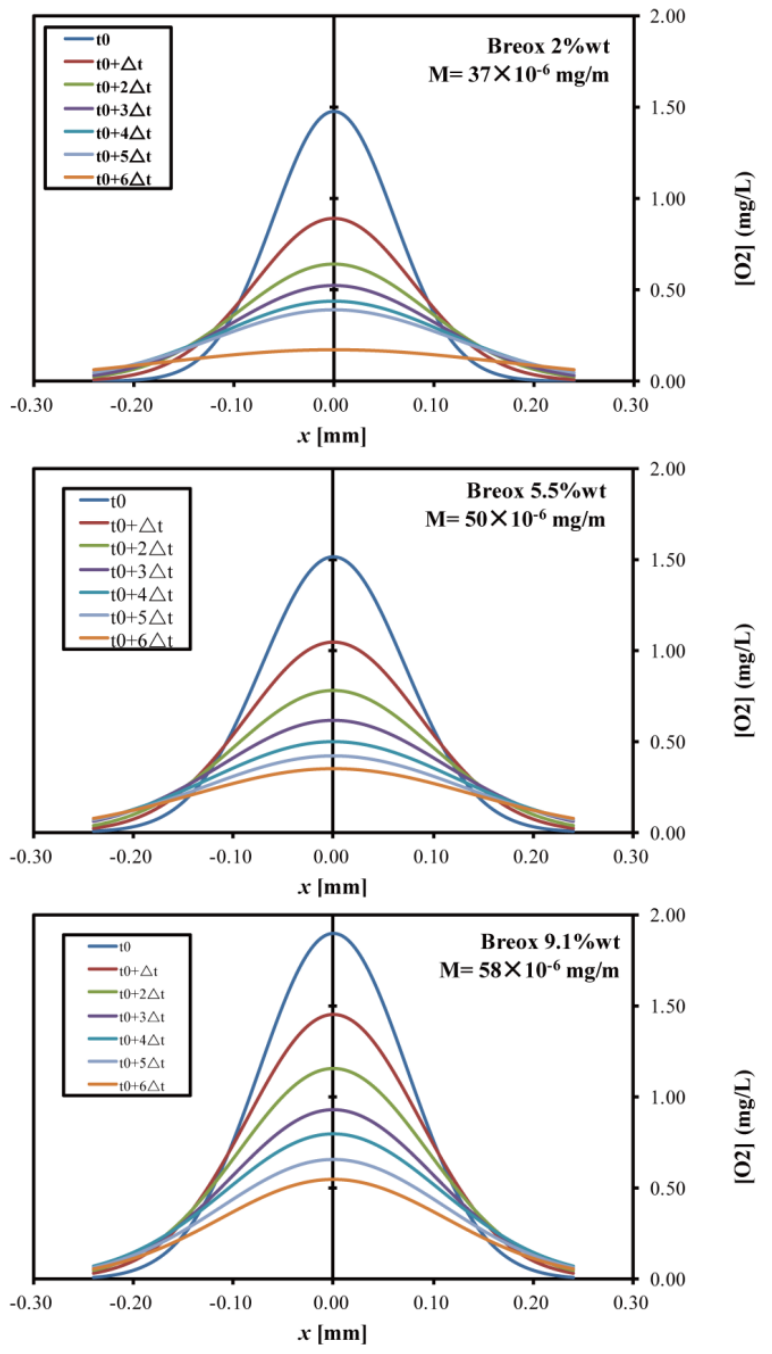

Fig. 9 Profile of dissolved oxygen concentration fields in the bubble wake cross sections in Breox solutions $(\Delta t=2 / 3 \mathrm{~s})$

As discussed before, for the Breox solutions, the dissolved oxygen diffuses from the spot center to the surroundings. The peak value of the profile drops rapidly in the first two moments and the oxygen field tends to become uniform. With increasing concentration of the solute, total transfer mass $M$ increases. For the PAAm solutions, a similar diffusion phenomenon is observed under the same concentration of solute except that the profiles look slimmer, indicating that the mass transfer is concentrated nearer the spot center. With the increasing concentration of the solute, the total transfer mass decreases, unlike the transfer in the Breox cases. 

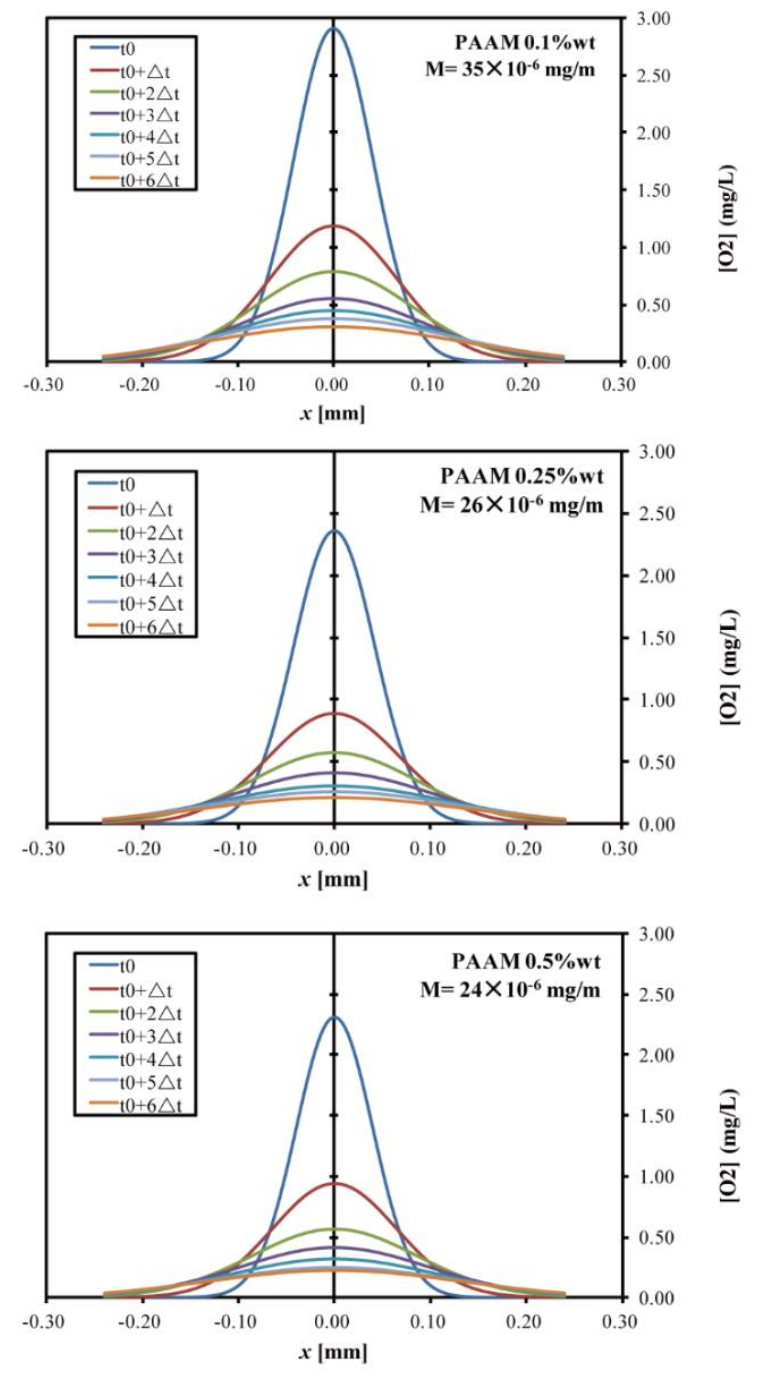

Fig. 10 Profile of dissolved oxygen concentration fields in the bubble wake cross sections in PAAm solutions $(\Delta t=2 / 3$ s $)$

As explained in Section 2.4.3, the diffusion coefficient can be calculated from the evolution of the partial spot area as a function of time. In the study, the value of $\eta$ is set to 1 . It has already been proved that the choice of $\eta$ does not affect the estimation of the diffusion coefficient ${ }^{30}$. Thus the slope of the curve $S_{\text {spot }}-t$ is equal to $4 \pi D$. The experimental data and the fitting curves are shown in Fig. 11. The result of the water case and the highest concentrations of the two polymer solutions were chosen for plotting in order to indicate the difference between them. It is found that all three sets of data show good linearity as the coefficient of determination for each is higher 
than $95 \%$. Moreover, the diffusion is reduced when the polymer solute is added.

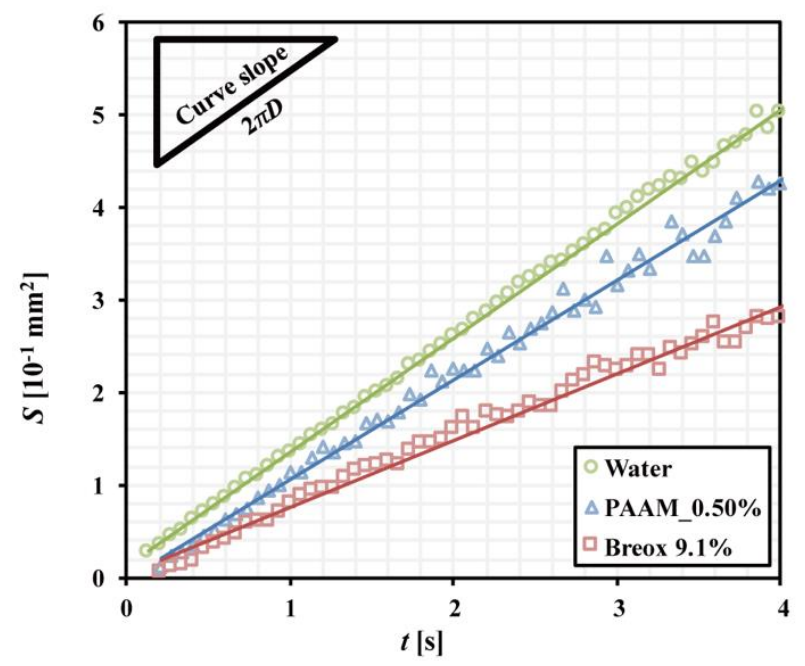

Fig. 11 Evolution of the spot area as a function of time

The complete results on the diffusion coefficient are given in Table 4, in which the diffusion coefficient is calculated with Eq. (14) and Eq. (27). It can be seen that there is no great difference between the results from the two methods. For both polymer solutions, the diffusion coefficient decreases with higher concentration of the solute.

Table 4. Results for the diffusion coefficient

\begin{tabular}{|c|c|c|c|}
\hline $\begin{array}{l}\text { Composition } \\
\text { [wt.] }\end{array}$ & & $\begin{array}{l}D \text { by Eq. }(25) \\
{\left[10^{-9} \mathrm{~m}^{2} / \mathrm{s}\right]}\end{array}$ & $\begin{array}{l}D \text { by Eq.(27) } \\
{\left[10^{-9} \mathrm{~m}^{2} / \mathrm{s}\right]}\end{array}$ \\
\hline Water & & $1.99 \pm 0.05$ & $2.00 \pm 0.15$ \\
\hline \multirow[t]{3}{*}{ + Breox } & $2.00 \%$ & $1.88 \pm 0.02$ & $1.86 \pm 0.09$ \\
\hline & $5.50 \%$ & $1.50 \pm 0.02$ & $1.48 \pm 0.06$ \\
\hline & $9.10 \%$ & $1.34 \pm 0.01$ & $1.32 \pm 0.05$ \\
\hline + PAAm & $0.10 \%$ & $1.88 \pm 0.02$ & $1.84 \pm 0.08$ \\
\hline
\end{tabular}


To investigate the effect of rheological properties on the diffusion, the diffusion coefficient is plotted versus viscosity (Fig. 12). It can be seen that diffusion is inhibited when the liquid media become more viscous. For the same viscosity, the diffusion coefficient is higher in PAAm solution than that in Breox solution and their difference tends to increase for higher viscosities. The result is also compared with the work by Dietrich et al. ${ }^{21}$ in which experiments were carried out to measure the diffusion coefficient of a bubble rising in glycerol, a non-polymer fluid. As can be seen in the figure, the diffusion is much more significant in the polymer than in non-polymer medium at the same viscosity. This might suggest that the polymer molecule can reduce diffusion less.

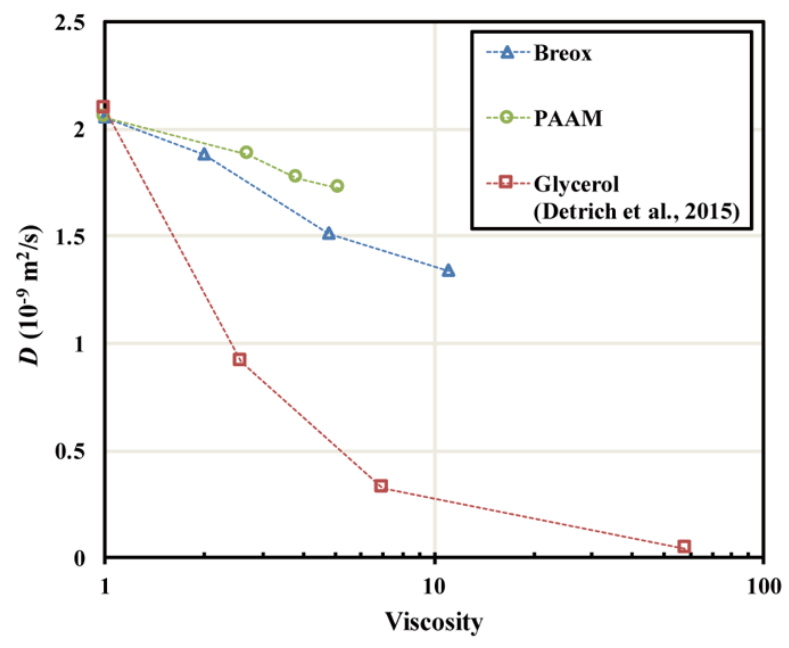

Fig. 12. Diffusion coefficient versus viscosity in different liquid media

\subsection{Mass transfer coefficient in different polymer media}

To estimate the impact of the fitting process on the mass transfer determination, the fluxes before and after fitting are calculated. The flux before fitting is regarded as a general oxygen spot that is calculated using Eq. (18). For the flux after fitting, the circular spot equation (Eq. (19)) is applied. 
The result is shown in Fig. 13. The case of water was chosen as the example for its wider range of flux values. Good consistency can be seen between the fluxes before fitting and after fitting, with a deviation of less than $5 \%$. In other solutions, since the flux value is more stable after the bubble passing, the deviation is even smaller, indicating that the dissolved oxygen spot on the bubble wake is more circular and can be better characterized by Eq. (12).

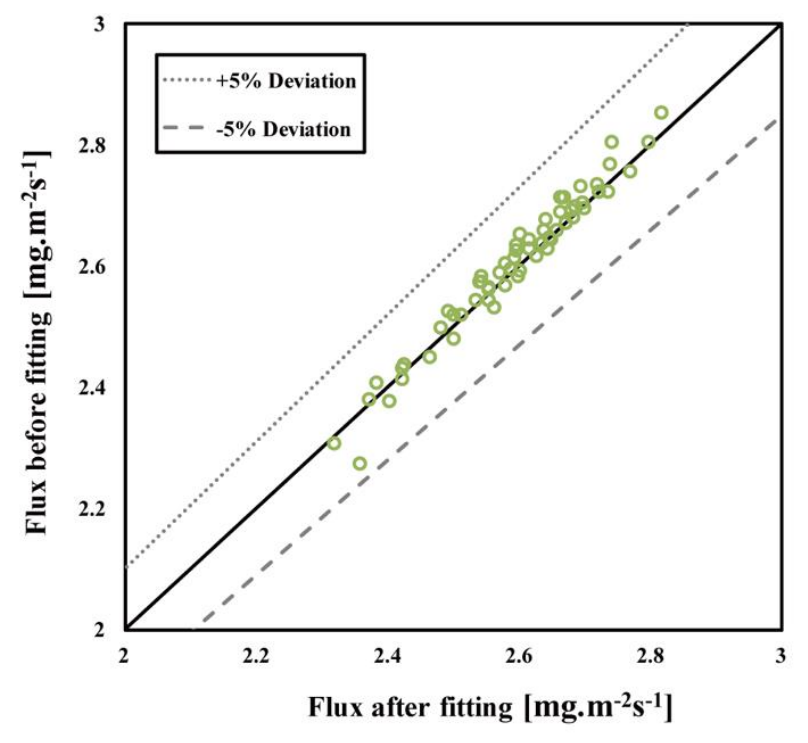

Fig. 13. Comparison between flux before fitting and flux after fitting (Example of water case)

The evolution of the estimated flux (after fitting) is plotted versus time for different fluids in Fig. 14. For the water case, the flux increases gradually in the first zone $(t<0.8 \mathrm{~s})$, which, experimentally, corresponds to the time necessary for the bubble to pass far enough to satisfy the non-convection hypothesis. Then, while the bubble continues to rise and the impact of the bubble passing tends to disappear in the second zone $(0.8<\mathrm{t}<3 \mathrm{~s})$, the flux value remains constant and the mathematical approach for determining the mass transfer is applicable in this region. After a longer time (third zone: $\mathrm{t}>3 \mathrm{~s}$ ), the experimental points start to scatter. This distortion is due to the broad distribution of the oxygen and the relatively low oxygen concentration in each pixel. Thus it is difficult to distinguish the oxygen transferred by the bubble from the background noise, 
which is estimated to be in the order of $0.1 \mathrm{mg} / \mathrm{L}$. This evolution result of the flux is consistent with the findings of Jimenez et al. ${ }^{20}$ in the first two zones. In the third zone, a diminution of flux was visualized in their study due to the fixed threshold setting the limit between mass transfer and the background. This distortion is improved since the threshold is not applied in the present image processing.

For the polymer cases, the evolution of the flux is similar to the water case. However, the zone of increase $(t<0.4 \mathrm{~s})$ is much shorter as the bubble rising velocity is lower in the polymer media. The long-chained molecules of the polymer are thought to be another factor that can maintain the stability of the fluid. Both factors can thus reduce the impact of the bubble motion on the fluid. When the Breox and PAAm cases are compared, the flux of the PAAm depends more on the concentration of the solute. For Breox solution at a different concentration, there is no obvious difference in the length of the first zone and the flux values of the second zone vary from 0.94 to $0.74 \mathrm{mg} \cdot \mathrm{m}^{-2} \cdot \mathrm{s}^{-1}$ when the solution becomes denser. On the other hand, for the PAAm cases, the length of the first zone is different for the three concentrations: it becomes shorter with higher concentration. The flux values of the second zone decrease from 0.85 to $0.43 \mathrm{mg} \cdot \mathrm{m}^{-2} \cdot \mathrm{s}^{-1}$ when the concentration increases from $0.1 \mathrm{wt} \%$ to $0.25 \mathrm{wt} \%$. This suggests that even a slight change of concentration will have an obvious impact on the mass transfer in PAAm solutions. The different results for these two polymer solutions are presumed to be related to their rheological properties. 

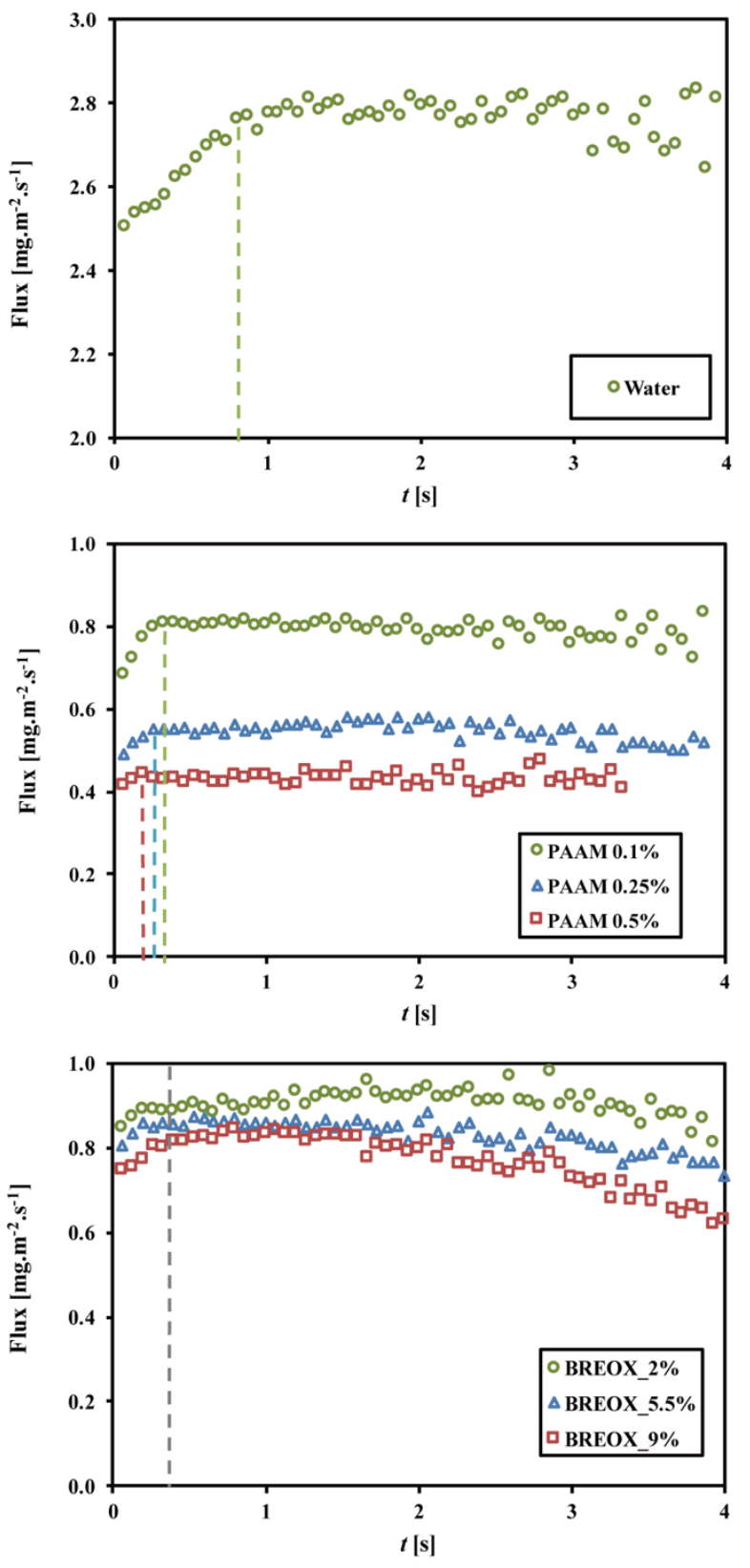

Fig. 14. Evolution of the estimated flux as a function of time in different liquids (Water, PAAm and Breox)

With the knowledge of the flux, the liquid side mass transfer coefficient can be calculated through Eq. (20) and Eq. (21). The results are shown in Table 5. It can be seen that the mass transfer coefficient, $k_{L}$, decreases dramatically, from $3.47 \times 10^{-4} \mathrm{~m} / \mathrm{s}$ to less than $1 \times 10^{-4} \mathrm{~m} / \mathrm{s}$, when the 
solute of polymer is added. Like the flux, the mass transfer coefficient decreases with the higher concentration of solute.

Table 5. Results for the liquid side mass transfer coefficient and the contaminated angle

\begin{tabular}{|c|c|c|c|c|c|c|c|}
\hline $\begin{array}{l}\text { Composition } \\
\text { [wt.] }\end{array}$ & & $\begin{array}{l}M / S \\
{\left[\mathrm{mg} / \mathrm{m}^{3}\right]}\end{array}$ & $\begin{array}{l}k_{L} \\
{\left[10^{-4} \mathrm{~m} / \mathrm{s}\right]}\end{array}$ & $\begin{array}{l}k_{L} \text { Frössling } \\
{\left[10^{-4} \mathrm{~m} / \mathrm{s}\right]}\end{array}$ & $\begin{array}{c}k_{L} \text { Higbie } \\
{\left[10^{-4} \mathrm{~m} / \mathrm{s}\right]}\end{array}$ & $\begin{array}{l}\varphi_{c a p} \\
{\left[{ }^{\circ}\right]}\end{array}$ & $\begin{array}{l}\varphi_{\text {cap_rec }} \\
{\left[{ }^{\circ}\right]}\end{array}$ \\
\hline Water & & 14.15 & $4.47 \pm 0.22$ & 1.70 & 8.20 & 31 & 101 \\
\hline \multirow[t]{3}{*}{+ Breox } & $2.00 \%$ & 8.75 & $1.16 \pm 0.09$ & 0.90 & 4.84 & 100 & 141 \\
\hline & $5.50 \%$ & 8.92 & $1.06 \pm 0.09$ & 0.65 & 4.08 & 81 & 132 \\
\hline & $9.10 \%$ & 9.36 & $0.95 \pm 0.07$ & 0.43 & 3.25 & 39 & 124 \\
\hline \multirow[t]{3}{*}{ + PAAm } & $0.10 \%$ & 11.09 & $1.06 \pm 0.09$ & 0.78 & 4.40 & 117 & 142 \\
\hline & $0.25 \%$ & 8.38 & $0.78 \pm 0.05$ & 0.67 & 3.98 & 112 & 151 \\
\hline & $0.50 \%$ & 7.23 & $0.69 \pm 0.05$ & 0.58 & 3.64 & 119 & 150 \\
\hline
\end{tabular}

Regarding the influence of the hydrodynamics of the bubble on the mass transfer, the velocity is reduced in polymer mainly due to the high viscosity. The $R e$ number of the bubble is much smaller in polymer solutions than in water so the flow field is more stable and less turbulent that will reduce the mass transfer. To some extent, this is a main reason for the mass transfer reduction. This is believed to be the main reason for the mass transfer reduction. However, in spite of the impact of velocity, we can estimate the mass transfer per unit area by diving the total transferred mass $M$ by the bubble surface area $S$ (results given in Table 5). It can be seen that the mass transfer per unit area for bubble rising in polymer is smaller than the result in water $(33 \%$ $38 \%$ decrease in Breox and 21\%-49\% decrease in PAAm). In particular, the bubble rises slower in more concentrated Breox solutions but the mass transfer per unit area is even bigger than the result in thinner solutions. Regarding this, the lower velocity is not only reason why the mass 
transfer is reduced in polymer solutions.

The experimental values are compared with the extreme cases of a clean bubble ${ }^{39}$ and a fully contaminated one $\mathrm{H}^{40}$.

$$
\begin{gathered}
k_{L_{\text {Higbie }}}=\frac{D}{d_{e q}}\left(1.13 R e^{0.5} S c^{0.5}\right) \\
k_{L_{\text {Frössling }}}=\frac{D}{d_{e q}}\left(2+0.66 R e^{0.5} S c^{0.33}\right)
\end{gathered}
$$

where $S c$ is the Schnidt Number, defined as $\mu_{L} / \rho_{L} D$. The results are listed in Table 5. Our experimental results lie between these two extreme cases. This implies that the bubble is partially contaminated, which makes sense since the water could hardly be considered as extra pure ${ }^{41}$ and the dye or polymer molecule also alters the bubble contamination. It can also find that all the experimental $k_{L}$ is more close to the value by Frössling model indicating that the bubble is at high contamination level.
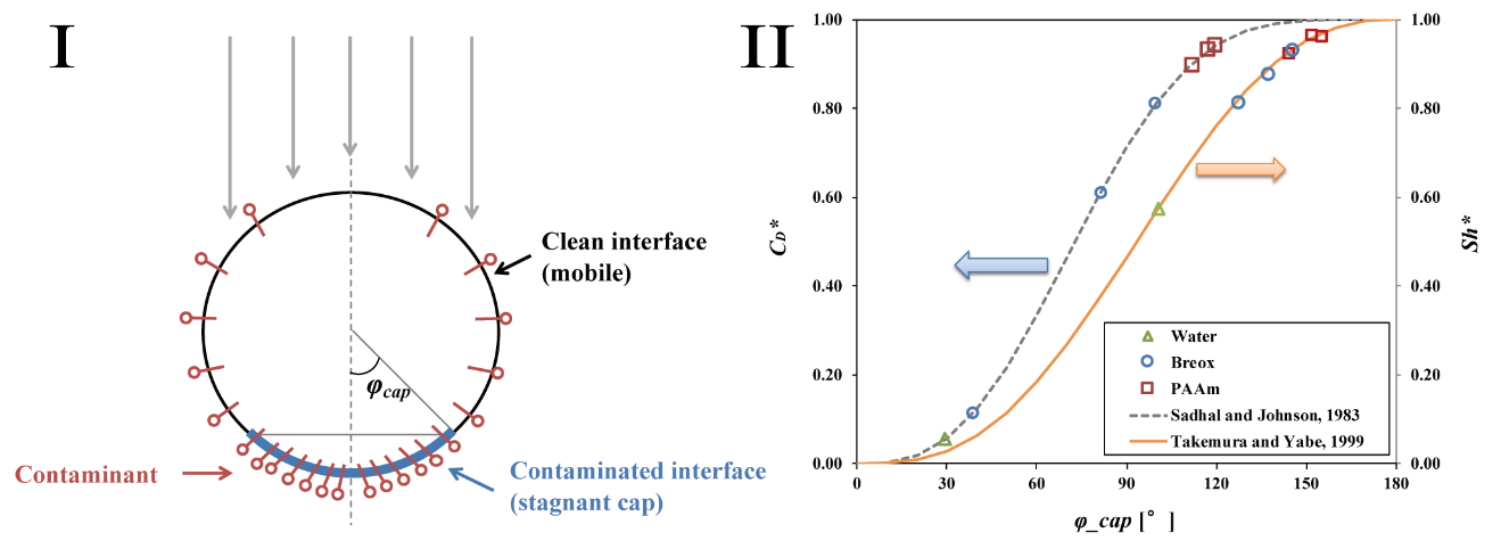

Fig. 15 I: Cap angle and contamination on a real bubble; II: Normalized drag coefficient vs stagnant cap angle (Left $y$-axis); Normalized Sherwood number vs stagnant cap angle (Right $y$-axis)

To investigate the contamination properties, the cap angle was introduced in Section 2.4.5. The result of each case is also listed in Table 5. The curve of the normalized drag coefficient as a function of stagnant cap angle is shown in Fig. 15-II (left $y$-axis). It can be found that For PAAm 
cases, the cap angles are large which is consistent with high contamination level. However, for other cases, the cap angles are too small regarding their relatively low mass transfer coefficients. It implies that the cap model, which is useful to characterize the hydrodynamics around the bubble, is no quite valid for characterizing the mass transfer to some extent. The explanation for this distortion is that, according the cap model by Sadhal and Johnson ${ }^{36}$, the contaminant distributes only on the stagnant cap. Thus for a little contaminated bubble with a small cap angle, there is no contaminant in most part of the bubble. However, for a real rising bubble, as depicted in Fig. 15-I, away from the cap, the concentration of the contaminant decreases gradually along the bubble surface. There are also some contaminants outside the cap and they will still affect the mass transfer. In this point of view, the cap angle is underestimated.

In order to find a better contamination angle, a normalized Sherwood number is $\operatorname{Sh}^{*}\left(\varphi_{\text {cap }}\right)$ defined as follows:

$$
S h^{*}=\frac{S h-S h^{m}}{S h^{i m}-S h^{m}}
$$

with the Sherwood number:

$$
\mathrm{Sh}=\frac{k_{L} D_{e q}}{D}
$$

The value $S h^{m}$ and $S h^{i m}$ can be obtained from the Higbie model for a clean bubble and from Frössling model for a fully contaminated one.

According to the work of Takemura and Yabe ${ }^{42}$ which carried out a numerical analysis of the dissolution process of the stagnant cap model, a correlation between $S h^{*}$ and the cap angle was proposed:

$$
S h^{*}=1-\left[1-C_{D}^{*}\left(\varphi_{c a p}\right)\right]^{0.5}
$$

The curve of the normalized Sherwood number as a function of cap angle is shown in Fig. 15-II (right $y$-axis). By using the mass transfer coefficient and the diffusivity measured in this study, the 
rectified cap angles $\varphi_{\text {cap_rec }}$ are calculated and given in Table 5. It can be found that rectified cap angles have a better agreement with the mass transfer result from the experiment. They are all larger than the original cap angles, especially for the water and Breox cases. Compared with the result in water, bubbles in polymer solutions always have a bigger cap angle. This suggests that the presence of polymer particles will enhance the contamination of the bubble surface from the mass transfer point of view and reduce the mass transfer. Moreover, when the concentration of the solute increases, the cap angle decreases for the Breox solutions but remains stable at high values for the PAAm cases. This can explain why $k_{L}$ decreases less in Breox solutions than in the PAAm solutions when the solutions become thicker.

\section{Conclusion}

Based on previous work ${ }^{19-21,30}$, the study of the mass transfer and the diffusion phenomenon in the wake of a bubble has been extended to water+polymer media here. By the technique of Planar Laser-Induced Fluorescence with Inhibition (PLIF-I), experiments were performed with air bubbles (Deq=1-1.4 mm) rising in various aqueous polymer solutions (PAAm: $0.1-0.5 \mathrm{wt} \%$; Breox: 2-9.1 wt\%). The diffusion coefficient and liquid side mass transfer coefficient were calculated for each case. The experimental results have been analyzed considering multiple factors (polymer type, the concentration of the solute, hydrodynamics of the bubble, and rheological properties of the fluid) and compared with the literature. The several conclusions drawn from the study can be summarized as follows:

1. As the bubble is quasi-spherical, the transferred mass is presented as a circular diffusion spot and the concentration field has a centrosymmetric distribution. Over time, the oxygen diffuses from the symmetric center to the surroundings. The diffusion is much more significant in the polymer than in the non-polymer vicous media with the same viscosity. This might suggest that the polymer molecule reduces diffusion less. 
2. A new method is proposed to determine the diffusion coefficient by analyzing the evolution of the parameter $B$ of the Gaussian equation as a function of time. The result is consistent with the calculations made by the previous method ${ }^{30}$.

3. The presence of the polymer reduces the mass transfer in water (with mass transfer coefficient dramatically decreasing from $4.47 \times 10^{-4} \mathrm{~m} / \mathrm{s}$ in water to less than $1 \times 10^{-4} \mathrm{~m} / \mathrm{s}$ in polymer solutions). This is due to the low bubble velocity and the enhanced contamination effect under our investigated condition. For the Breox solution, the contamination angle decreases with the polymer concentration while for PAAm the contamination effect remains high with the polymer concentration.

4. The contamination effect can be quantified by the stagnant cap model but the result is then underestimated for the mass transfer modeling. By using the normalized Sherwood number, a rectified contamination angle is proposed which is found more consistent with the mass transfer result by the experiment. For the Breox solution, the total mass transferred increases with the polymer concentration (decreasing contamination) but the mass flux decreases due to viscous effects (decreasing slip velocity). For the PAAm solution, the total mass transferred decreases with the polymer concentration (higher contamination) and the mass flux decreases more drastically than with the Breox solution.

\section{Nomenclature}

\section{Latin Symbols}

$D \quad$ diffusion coefficient $\left[\mathrm{m}^{2} / \mathrm{s}\right]$

$\left[\mathrm{O}_{2}\right]_{\text {bulk }} \quad$ oxygen concentrations far from the spot center $[\mathrm{mg} / \mathrm{L}]$

$\left[\mathrm{O}_{2}\right]_{\text {sat }} \quad$ oxygen concentrations at saturation $[\mathrm{mg} / \mathrm{L}]$

$\left[\mathrm{O}_{2}\right] \quad$ oxygen concentration $[\mathrm{mg} / \mathrm{L}]$

$A \quad$ parameter of Gaussian equation $[\mathrm{mg} / \mathrm{L}]$

$B \quad$ parameter of Gaussian equation $\left[\mathrm{mm}^{2}\right]$

$C \quad$ parameter of Gaussian equation $[\mathrm{mg} / \mathrm{L}]$

$C_{D} \quad$ drag coefficient of the bubble [-]

$C_{\text {Dim }} \quad$ drag coefficient for a fully contaminated bubble [-] 


\begin{tabular}{|c|c|}
\hline$C_{D m}$ & drag coefficient for a clean bubble [-] \\
\hline$D_{e q}$ & equivalent diameter $[\mathrm{mm}]$ \\
\hline$F_{O 2}$ & oxygen flow rate $[\mathrm{mg} / \mathrm{s}]$ \\
\hline$G$ & gray level [-] \\
\hline$G_{0}$ & gray level without oxygen [-] \\
\hline$I_{0}$ & fluorescence intensities without quencher [-] \\
\hline$I_{Q}$ & fluorescence intensities with quencher [-] \\
\hline$k_{L}$ & liquid side mass transfer coefficient $[\mathrm{m} / \mathrm{s}]$ \\
\hline$K_{S V}$ & Stern-Volmer constant $[\mathrm{L} / \mathrm{mg}]$ \\
\hline$l$ & length of the bubble $[\mathrm{mm}]$ \\
\hline$M$ & total mass transferred in a planar concentration field $[\mathrm{mg} / \mathrm{mm}]$ \\
\hline$m_{O 2}$ & mass transferred by the bubble $[\mathrm{mg}]$ \\
\hline$r$ & cylindrical coordinate $[\mathrm{mm}]$ \\
\hline $\operatorname{Re}$ & Reynolds number $\operatorname{Re}=U D_{e q} \rho / \mu[-]$ \\
\hline$S$ & diffusion spot area $\left[\mathrm{mm}^{2}\right]$ \\
\hline$S_{b}$ & bubble surface area $\left[\mathrm{mm}^{2}\right]$ \\
\hline$S c$ & Schmidt number, $S c=\mu / \rho D[-]$ \\
\hline$t$ & time $[\mathrm{s}]$ \\
\hline$V_{b}$ & bubble volume $\left[\mathrm{mm}^{3}\right]$ \\
\hline$U_{b}$ & bubble rising velocity $[\mathrm{mm} / \mathrm{s}]$ \\
\hline$w$ & width of the bubble $[\mathrm{mm}]$ \\
\hline$x$ & abscissa $[\mathrm{mm}]$ \\
\hline$X$ & abscissa of the spot center [mm] \\
\hline$y$ & ordinate $[\mathrm{mm}]$ \\
\hline$Y$ & ordinate of the spot center $[\mathrm{mm}]$ \\
\hline$z$ & cylindrical-coordinate $[\mathrm{mm}]$ \\
\hline \multicolumn{2}{|c|}{ Greek Symbols } \\
\hline$\gamma$ & shear rate $\left[\mathrm{s}^{-1}\right]$ \\
\hline$\delta$ & side length of a single pixel [mm] \\
\hline$\eta$ & positive integer parameter [-] \\
\hline$\theta$ & cylindrical-coordinate $\left[{ }^{\circ}\right]$ \\
\hline$\mu$ & dynamic viscosity $[\mathrm{Pa} \cdot \mathrm{s}]$ \\
\hline$\rho$ & density $\left[\mathrm{kg} / \mathrm{m}^{3}\right]$ \\
\hline$\sigma$ & surface tension $[\mathrm{N} / \mathrm{m}]$ \\
\hline$\varphi_{c a p}$ & contamination angle $\left[{ }^{\circ}\right]$ \\
\hline$\chi$ & aspect ratio $[-]$ \\
\hline
\end{tabular}

\section{Supporting Information}

The Supporting Information is available free of charge on the ACS Publications website. 
S1. Error analysis

S2. Derivation of total transferred mass $M$

Table S1. Rheological results of the liquid

Table S2. Hydrodynamic results of the rising bubble

Table S3. Results of diffusion

Table S4. Results of mass transfer

Table S5. Results of normalized drag coefficient and cap angle

Table S6. Results of normalized Sherwood number and cap angle

\section{Acknowledgments}

The financial assistance provided for F. XU by the China Scholarship Council is gratefully acknowledged. The federation Fermat is also thanked for its leading-edge material support.

\section{References}

(1) Billet, R.; Schultes, M. Predicting Mass Transfer in Packed Columns. Chem. Eng. Technol. 2004, 16 (1), 1-9.

(2) Krishna, R.; van Baten, J. M. Mass Transfer in Bubble Columns. Catal. Today 2003, 7980,67-75.

(3) Albal, R. S.; Shah, Y. T.; Schumpe, A.; Carr, N. L. Mass Transfer in Multiphase Agitated Contactors. Chem. Eng. J. 1983, 27 (2), 61-80.

(4) Heertjes, P. M.; Holve, W. A.; Talsma, H. Mass Transfer between Isobutanol and Water in a Spray-Column. Chem. Eng. Sci. 1954, 3 (3), 122-142.

(5) Akita, K.; Yoshida, F. Gas Holdup and Volumetric Mass Transfer Coefficient in Bubble Columns. Effects of Liquid Properties. Ind. Eng. Chem. Process Des. Dev. 1973, 12 (1), 76-80.

(6) Akita, K.; Yoshida, F. Bubble Size, Interfacial Area, and Liquid-Phase Mass Transfer Coefficient in Bubble Columns. Ind. Eng. Chem. Process Des. Dev. 1974, 13 (1), 84-91.

(7) Hughmark, G. A. Holdup and Mass Transfer in Bubble Columns. Ind. Eng. Chem. Process Des. Dev. 1967, 6 (2), 218-220.

(8) Wolff, C.; Briegleb, F. U.; Bader, J.; Hektor, K.; Hammer, H. Measurements with MultiPoint Microprobes: Effect of Suspended Solids on the Hydrodynamics of Bubble Columns for Application in Chemical and Biotechnological Processes. Chem. Eng. Technol. 1990, 13 (1), 172-184.

(9) Bork, O.; Schlueter, M.; Raebiger, N. The Impact of Local Phenomena on Mass Transfer 
in Gas-Liquid Systems. Can. J. Chem. Eng. 2005, 83 (4), 658-666.

(10) Roy, S.; Duke, S. R. Visualization of Oxygen Concentration Fields and Measurement of Concentration Gradients at Bubble Surfaces in Surfactant-Contaminated Water. Exp. Fluids 2004, 36 (4), 654-662.

(11) Jimenez, M.; Dietrich, N.; Hebrard, G. A New Method for Measuring Diffusion Coefficient of Gases in Liquids by Plif. Mod. Phys. Lett. B 2012, 26 (6), 1150034.

(12) Jimenez, M.; Dietrich, N.; Grace, J. R.; Hébrard, G. Oxygen Mass Transfer and Hydrodynamic Behaviour in Wastewater: Determination of Local Impact of Surfactants by Visualization Techniques. Water Res. 2014, 58, 111-121.

(13) Butler, C.; Cid, E.; Billet, A.-M. Modelling of Mass Transfer in Taylor Flow: Investigation with the PLIF-I Technique. Chem. Eng. Res. Des. 2016, 115, 292-302.

(14) Butler, C.; Lalanne, B.; Sandmann, K.; Cid, E.; Billet, A.-M. Mass Transfer in Taylor Flow: Transfer Rate Modelling from Measurements at the Slug and Film Scale. Int. J. Multiph. Flow 2018, 105, 185-201.

(15) Kück, U. D.; Schlüter, M.; Räbiger, N. Investigation on Reactive Mass Transfer at Freely Rising Gas Bubbles http://ufdc.ufl.edu/UF00102023/00202 (accessed Nov 2, 2015).

(16) Saito, T.; Toriu, M. Effects of a Bubble and the Surrounding Liquid Motions on the Instantaneous Mass Transfer across the Gas-Liquid Interface. Chem. Eng. J. 2015, 265, $164-175$.

(17) Stöhr, M.; Schanze, J.; Khalili, A. Visualization of Gas-Liquid Mass Transfer and Wake Structure of Rising Bubbles Using PH-Sensitive PLIF. Exp. Fluids 2009, 47 (1), 135-143.

(18) Rüttinger, S.; Spille, C.; Hoffmann, M.; Schlüter, M. Laser-Induced Fluorescence in Multiphase Systems. ChemBioEng Rev. 2018, 5 (4), 253-269.

(19) Francois, J.; Dietrich, N.; Guiraud, P.; Cockx, A. Direct Measurement of Mass Transfer around a Single Bubble by Micro-PLIFI. Chem. Eng. Sci. 2011, 66 (14), 3328-3338.

(20) Jimenez, M.; Dietrich, N.; Hébrard, G. Mass Transfer in the Wake of Non-Spherical Air Bubbles Quantified by Quenching of Fluorescence. Chem. Eng. Sci. 2013, 100, 160-171.

(21) Dietrich, N.; Francois, J.; Jimenez, M.; Cockx, A.; Guiraud, P.; Hébrard, G. Fast Measurements of the Gas-Liquid Diffusion Coefficient in the Gaussian Wake of a Spherical Bubble. Chem. Eng. Technol. 2015, 38 (5), 941-946.

(22) Levitsky, S. P.; Shulman, Z. P. Bubbles in Polymeric Liquids: Dynamics and Heat-Mass Transfer, 1 edition.; Technomic Publishing Co.: Lancaster, 1995.

(23) Dani, A.; Guiraud, P.; Cockx, A. Local Measurement of Oxygen Transfer around a Single Bubble by Planar Laser-Induced Fluorescence. Chem. Eng. Sci. 2007, 62 (24), 7245-7252.

(24) Hanyu, K.; Saito, T. Dynamical Mass-Transfer Process of a CO2 Bubble Measured by Using LIF/HPTS Visualisation and Photoelectric Probing. Can. J. Chem. Eng. 2010, 88 (4), 551-560.

(25) Kück, U. D.; Schlüter, M.; Räbiger, N. Local Measurement of Mass Transfer Rate of a Single Bubble with and without a Chemical Reaction. J. Chem. Eng. Jpn. 2012, 45 (9), 708-712.

(26) Valiorgue, P.; Souzy, N.; Hajem, M. E.; Hadid, H. B.; Simoëns, S. Concentration Measurement in the Wake of a Free Rising Bubble Using Planar Laser-Induced Fluorescence (PLIF) with a Calibration Taking into Account Fluorescence Extinction Variations. Exp. Fluids 2013, 54 (4), 1-10.

(27) Valiorgue, P.; Souzy, N.; Hajem, M. E.; Hadid, H. B.; Simoëns, S. Erratum to: Concentration Measurement in the Wake of a Free Rising Bubble Using Planar LaserInduced Fluorescence (PLIF) with a Calibration Taking into Account Fluorescence Extinction Variations. Exp. Fluids 2014, 55 (4), 1-2.

(28) Huang, J.; Saito, T. Influence of Bubble-Surface Contamination on Instantaneous Mass Transfer. Chem. Eng. Technol. 2015, 38 (11), 1947-1954.

(29) Huang, J.; Saito, T. Influences of Gas-Liquid Interface Contamination on Bubble Motions, 
Bubble Wakes, and Instantaneous Mass Transfer. Chem. Eng. Sci. 2017, 157, 182-199.

(30) Xu, F.; Jimenez, M.; Dietrich, N.; Hébrard, G. Fast Determination of Gas-Liquid Diffusion Coefficient by an Innovative Double Approach. Chem. Eng. Sci. 2017, 170 (Supplement C), 68-76.

(31) Roudet, M.; Billet, A.-M.; Cazin, S.; Risso, F.; Roig, V. Experimental Investigation of Interfacial Mass Transfer Mechanisms for a Confined High-Reynolds-Number Bubble Rising in a Thin Gap. AIChE J. 2017, 63 (6), 2394-2408.

(32) Kong, G.; Buist, K. A.; Peters, E. A. J. F.; Kuipers, J. A. M. Dual Emission LIF Technique for $\mathrm{PH}$ and Concentration Field Measurement around a Rising Bubble. Exp. Therm. Fluid Sci. 2018, 93, 186-194.

(33) Kreiba, A. The Rheological Properties of Aqueous Polyacrylamide Solutions, Concordia University: Canada, 2000.

(34) Jimenez, M. Etude du transfert de matière gaz/liquide en milieux complexes: quantification du transfert d'oxygène par techniques optiques, INSA, 2013.

(35) Stern, O.; Volmer, M. On the Quenching Time of Fluorescence. Phys. Z 1919, 20, 183188.

(36) Sadhal, S. S.; Johnson, R. E. Stokes Flow Past Bubbles and Drops Partially Coated with Thin Films. Part 1. Stagnant Cap of Surfactant Film - Exact Solution. J. Fluid Mech. 1983, 126, 237-250.

(37) Schiller, L.; Naumann, A. Ueber Die Grundlegenden Berechnungen Bei Der Schwerkraftaufbereitung. Ver Deut Ing 1933, 77, 318-320.

(38) Mei, R.; Klausner, J. F.; Lawrence, C. J. A Note on the History Force on a Spherical Bubble at Finite Reynolds Number. Phys. Fluids 1994, 6 (1), 418-420.

(39) Higbie, R. The Rate of Absorption of a Pure Gas Into a Still Liquid During Short Periods of Exposure, by Ralph Higbie, Based on Doctor's Dissertation, Submitted at the University of Michigan; 1935.

(40) Frössling, N. Uber Die Verdunstung Fallender Tropfen. Beitr Geophys Gerlands 1938, 52, 170-216.

(41) Alves, S. S.; Orvalho, S. P.; Vasconcelos, J. M. T. Effect of Bubble Contamination on Rise Velocity and Mass Transfer. Chem. Eng. Sci. 2005, 60 (1), 1-9.

(42) Takemura, F.; Yabe, A. Rising Speed and Dissolution Rate of a Carbon Dioxide Bubble in Slightly Contaminated Water. J. Fluid Mech. 1999, 378, 319-334. 


\section{For Table of Contents Only}

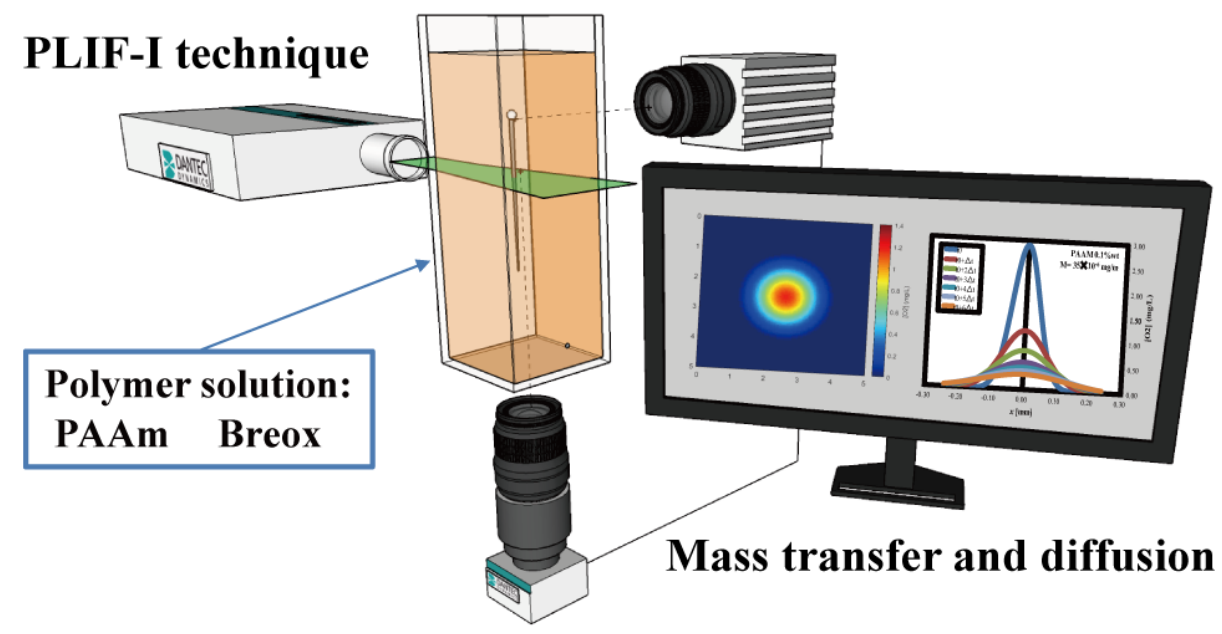

